\title{
An Overview of Cooperative Robotics in Agriculture
}

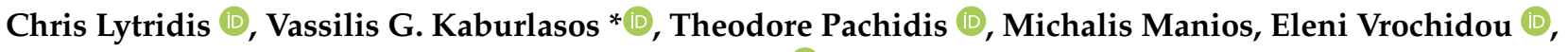 \\ Theofanis Kalampokas and Stamatis Chatzistamatis (1)
}

Human-Machines Interaction (HUMAIN) Lab, Department of Computer Science, International Hellenic University (IHU), 65404 Kavala, Greece; lytridic@cs.ihu.gr (C.L.); pated@cs.ihu.gr (T.P.); m.manios@cs.ihu.gr (M.M.); evrochid@teiemt.gr (E.V.); theokala@cs.ihu.gr (T.K.); stami@emt.ihu.gr (S.C.)

* Correspondence: vgkabs@teiemt.gr; Tel.: +30-2510-462-320

check for

updates

Citation: Lytridis, C.; Kaburlasos, V.G.; Pachidis, T.; Manios, M.;

Vrochidou, E.; Kalampokas, T.;

Chatzistamatis, S. An Overview of Cooperative Robotics in Agriculture. Agronomy 2021, 11, 1818. https:// doi.org/10.3390/agronomy11091818

Academic Editors: Francisco

Manzano Agugliaro and

Esther Salmerón-Manzano

Received: 11 August 2021

Accepted: 6 September 2021

Published: 10 September 2021

Publisher's Note: MDPI stays neutral with regard to jurisdictional claims in published maps and institutional affiliations.

Copyright: (c) 2021 by the authors. Licensee MDPI, Basel, Switzerland. This article is an open access article distributed under the terms and conditions of the Creative Commons Attribution (CC BY) license (https:// creativecommons.org/licenses/by/ $4.0 /)$.

\begin{abstract}
Agricultural robotics has been a popular subject in recent years from an academic as well as a commercial point of view. This is because agricultural robotics addresses critical issues such as seasonal shortages in manual labor, e.g., during harvest, as well as the increasing concern regarding environmentally friendly practices. On one hand, several individual agricultural robots have already been developed for specific tasks (e.g., for monitoring, spraying, harvesting, transport, etc.) with varying degrees of effectiveness. On the other hand, the use of cooperative teams of agricultural robots in farming tasks is not as widespread; yet, it is an emerging trend. This paper presents a comprehensive overview of the work carried out so far in the area of cooperative agricultural robotics and identifies the state-of-the-art. This paper also outlines challenges to be addressed in fully automating agricultural production; the latter is promising for sustaining an increasingly vast human population, especially in cases of pandemics such as the recent COVID-19 pandemic.
\end{abstract}

Keywords: agricultural robots; agriculture 4.0/5.0; cooperative robots; farming automation

\section{Introduction}

The popular term Precision Agriculture, or PA for short, has been defined as "a management strategy that uses electronic information and other technologies to gather, process, and analyze spatial and temporal data for the purpose of guiding targeted actions that improve efficiency, productivity, and sustainability of agricultural operations" [1]. Based on this definition, the introduction of robots in agricultural tasks can serve the purpose of PA by taking advantage of sophisticated equipment for accurate measurements, management, and operations. Hence, an analysis of the effects of the introduction of agricultural robots in the workforce was presented in [2]. Systematic reviews that widely cover research in the field of agricultural robots can be found in [3-5]. These studies show a wide range of agricultural applications that can be achieved by replacing humans with autonomous machines. The objective of introducing robots in agriculture are mainly (a) to improve efficiency and productivity, (b) to counter labor shortages of seasonal workers, and (c) to perform laborious and possibly dangerous tasks. Those developments in agriculture can be interpreted in a more general, industrial context as follows.

Industry 1.0 or, equivalently, the (classic) industrial revolution, has been called the transition from manual production to mechanical (steam) production from the late 18th century to the early 19th century. The second industrial revolution (Industry 2.0), from the late 19th century to the early 20th century, was shaped by the widespread use of electricity. The third industrial revolution (Industry 3.0), in the second half of the 20th century, was shaped by the widespread use of digital computers. Currently, the fourth industrial revolution (Industry 4.0) is driven by advanced artificial intelligence as well as by the Internet. Corresponding developments can be observed in agricultural technology whose most recent developments are outlined next.

The term "Agriculture 3.0" has been proposed as an alternative to "Precision Agriculture" [6]. Agriculture 3.0 can be interpreted as a domain-specific extension of Industry 
3.0 in agriculture. Note that PA, which includes the application of personalized practices (i.e., inputs) based on local measurements, may not be suitable for all agricultural tasks. In particular, the production of certain high-quality agricultural products may require manual skills based on empirical knowledge. For example, vinicultural tasks such as harvesting, pruning, spraying, tying, etc. require the aforementioned skills.

Lately, the term "Agriculture 4.0" has been proposed as a domain-specific extension of "Industry 4.0" to agriculture [6,7]. More specifically, among other things, "Agriculture $4.0^{\prime \prime}$ refers to a massive automation of skillful manual agricultural tasks. The work here has been motivated by an ongoing project regarding the development of a team of cooperative robots, including ground robot vehicles as well as unmanned aerial vehicles, for vinicultural applications [6], where emphasis is given to the engagement of mechanical hands with many $(>20)$ degrees of freedom toward reproducing the skillfulness of the human hand in selected vinicultural tasks.

The cooperative robotics reviewed in this work could be regarded as a precursor, in agriculture, of a more general industrial trend toward a cooperative integration of humans with robots/machines, namely "Industry 5.0" [8]. More specifically, cooperative robotics can be a future "Agriculture 5.0" technology that integrates humans with robots in agricultural applications. In the latter context, a technological challenge regards the development of effective models to support interaction between humans and/or robots. This work, in the discussion section below, proposes a novel information processing paradigm for supporting cooperative robots in agriculture.

Technological advances in sensing and actuation as well as machine learning have allowed more agricultural tasks to be feasible by autonomous machines. Such tasks range in all stages of cultivation from land preparation and sowing, to monitoring and harvesting. Commercial agricultural robots are already available, and more are expected to appear in the next years as technologies such as machine vision and dexterous grasping become more mature. However, the introduction of multiple cooperating robots in the field can have good prospects in the reduction of production costs and the improvement of operational efficiency. This paper presents an overview of research in the field of cooperative robotics in the context of agriculture. The incentive behind this work is the fact that even though there are numerous studies regarding advances in agricultural robots and their underlying technologies, there are no studies that comprehensively survey the utilization of cooperation in agricultural robotic applications.

The paper is structured as follows: Section 2 describes the methodology followed for compiling relevant research works. Section 3 details our results regarding cooperative agricultural robots, including relevant statistics. Finally, Section 4 summarizes the contribution of this work, including discussions for potential future work.

\section{Materials and Methods}

The sources used for the compilation of the present review were the databases of Google Scholar, ScienceDirect, Scopus, IEEE Xplorer, and Wiley. The criteria for selecting the research to be included in this paper were the following: (a) work from the last 15 years was reviewed, (b) aerial or ground robots had to demonstrate autonomy as well as cooperative and coordination skills, and (c) the application area had to be in agriculture exclusively, i.e., no robots executing general-purpose cooperation algorithms were included. Furthermore, among articles by the same author(s) that report research results incrementally, only the most recent ones were considered in the present review.

Note that, sometimes, a team of robots is employed "in parallel" such that each robot is operating alone on a different land parcel without interacting with another robot. Such teams of robots have not been considered here. Instead, the interest of this work is in teams of robots interacting with one another.

This paper presents statistical results regarding papers based on the date of research as well as the country where the research took place. For the former, the publication year 
was used; for the latter, a country was defined by the affiliation of the first author, even though several articles are the result of international collaborations.

In total, 77 articles were compiled and (a) reviewed and (b) statistically analyzed regarding their (b.1) type of publication, (b.2) research topic, (b.3) geographical region of the first author, (b.4) country of origin of the first author, and (b.5) year of publication. Details regarding our review analysis are presented next.

\section{Cooperative Agricultural Robotics}

The reviewed papers were categorized into five main research topics where cooperation is found in agricultural robotics: (a) human-robot cooperation, or "human-robot" for short, (b) cooperative Unmanned Aerial Vehicles (UAVs), or "multi-UAV" for short, (c) cooperative Unmanned Ground Vehicles (UGVs), or "multi-UGV" for short, (d) Hybrid teams of UAVs and UGVs, or "UAV/UGV" for short, and (e) cooperative manipulation by multi-arm systems, or "manipulators" for short.

\subsection{Human-Robot Cooperation (Human-Robot)}

The majority of agricultural work is currently being performed by humans either manually or using human-operated machines or equipment. In recent years, there have been many attempts to automate tasks and produce fully autonomous robots. However, some tasks cannot yet be carried out by a single robot in a reliable and efficient manner. For this reason, collaboration between humans and robots has been considered [9-12].

When a human and a robot must work together towards a common objective, there are several ways in which control can be realized, such as through remote control, supervisory control, or cooperative control [13]. In this section, the focus will be on examples of cooperative human-robot control in agricultural applications.

To realize cooperative control, some interface between the robot and the human must be established, such that information is shared and some level of control from the part of the human is achieved. For example, in [14], the usability of different types of user interfaces was studied for the control of a semi-autonomous vineyard sprayer robotic system. In this case, the robot can perform some tasks autonomously, but the human operator can intervene through a user interface. In [15], tractor steering was achieved using signals from an electromyographic (EMG) human-machine interface put on a human tractor driver. Apart from interface types, other works explore the idea that, depending on the conditions, different levels of cooperation may be needed. For instance, in [16], a semi-autonomous system was presented. The system used a three-layer architecture that includes a servo control, autonomous control, and manual operation. The operator can either manually operate the vehicle or can act as a supervisor of the autonomous vehicle, able to intervene at appropriate times through an interface. In [17], automatic melon recognition was investigated. The objective was to evaluate the effectiveness of collaboration between a human and a robot in a target recognition task. Four collaboration levels were investigated, ranging from target selection, performed by the human operator, to automatic target selection, performed by the system. The study showed higher detection rates in the collaborative detection case compared to either manual or autonomous detection cases. In a later study [18], the authors used an objective function for the performance of the collaborative task (as defined in [19]) to dynamically alter the collaboration levels during the melon recognition task.

A mathematical programming framework for optimizing human-robot collaboration was proposed in [20]. The framework considers the question of when interaction of the human operator with the robotic system is most economically beneficial. To validate the framework, simulations of citrus robotic harvesting were implemented, and showed how the robotic system required human collaboration in order to compensate for inefficient components of the system.

In [21], human action recognition by robots in an agricultural task was investigated. More specifically, human participants equipped with wearable sensors for data acquisition 
were asked to perform the common agricultural task of lifting and carrying a crate. The objective was to determine whether the robots, using appropriate machine learning models and classification algorithms, could identify the actions of the human participants throughout the task. The authors reported an average accuracy in action recognition of $85.6 \%$. In an earlier work [22], an omni-directional stereo vision camera mounted on a robot tractor was employed for human detection. The system was validated using field tests, which showed that the human could be detected successfully in the range of 4 to $11 \mathrm{~m}$.

In the precision spraying task described in [23], the authors reported a reduction of up to $50 \%$ in terms of spraying material. The proposed human-robot collaboration framework aimed at minimizing the false positives in spraying targets, based on images collected by an on-board camera. Depending on the selected cooperation level, target detection can be fully automatic, completely manual by the remote operator, or the operator can adjust the automatically marked targets.

In $[24,25]$, an emulated cooperative strawberry recognition task was presented. In this work, a robot navigated the environment and relayed the images with the automatically recognized targets (together with the degrees of recognition confidence) to human test operators. The user could then accept the recognized targets or not. Based on questionnaires completed by the test users, they reported that they preferred a robot behavior where automatic recognition yields more false positives as opposed to a behavior which results in more false negatives.

A model which enables coordination between humans, robots, sensors, and software agents (i.e., a cyber-physical organization) for gathering unspecified crops and fruit was introduced in [26]. The proposed model consisted of five connected layers, namely network, communication, interaction, organization, and collective intelligence. Through this layered approach, the objective was to achieve indistinguishability, i.e., to enable the system to achieve the desired goal regardless of the actor, either human or machine, that performs the task.

A human-robot skill transfer interface aimed at improving UAV pesticide delivery was proposed in [27]. In this scheme, the UAV was first instructed a trajectory by a human operator via the interface. Then, the accuracy of the trajectory derived in the demonstration phase was improved using an adaptive cubature Kalman filter. Finally, the UAV could follow the resulting trajectory using the stored position and velocity data. The methodology was tested in both simulation through SIMULINK and field experiments using an actual $\mathrm{UAV}$ in a commercial canola field.

The cooperative tea harvesting system proposed in [28] used a robot with a camera to detect a marker-carrying human and move by his side by estimating position differences. This coordinated motion then made it easy for the human operator to guide the robot, which had the harvesting device mounted on it, through the field, compared to the standard tea plucking machine which requires two workers.

The presence of a human in an agricultural task requires additional considerations to ensure the health and safety of the workers and to increase the level of trust in humanrobot interaction among agricultural workers [29,30]. The study presented in [31] identified the main risk factors in human-robot collaboration in agricultural tasks and proposed methods for safe collaboration by minimizing potential hazards. Moreover, in the pilot study presented in [32], the authors conducted field experiments both in open and indoors environments, where field workers harvesting strawberries evaluated their work carried out alongside the Thorvald robot. The data collected from this study can be used for the design of collaborative systems in terms of the safety aspects.

Figure 1 shows examples of systems where human-robot cooperation is exploited. 


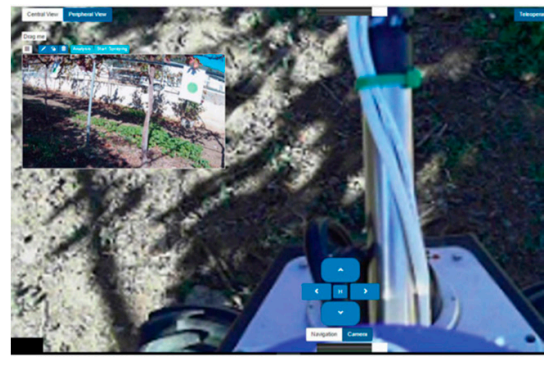

(a) Agribot interface [14]

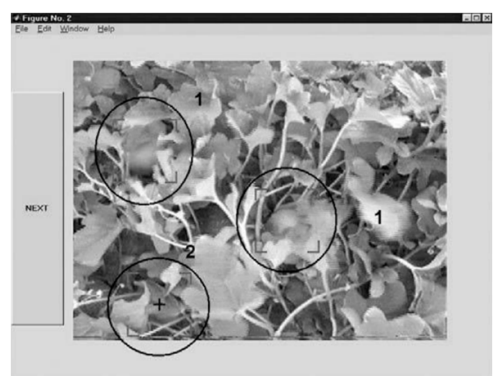

(b) Collaborative target recognition [17]

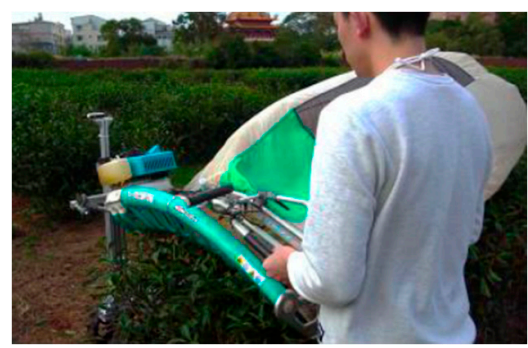

(c) Tea plucking [28]

Figure 1. Examples of human-robot cooperative systems.

Table 1 summarizes the basic features of the reviewed studies.

Table 1. Summary of the reviewed human-robot cooperation studies in agriculture.

\begin{tabular}{ccccc}
\hline Ref. & Task & Objective & Type of Study & Cooperation Strategy \\
\hline$[14]$ & Spraying & Vineyard & Field trial & User confirmation of machine vision \\
{$[15]$} & Driving & N/A & Field trial & EMG interface \\
{$[16]$} & Driving & N/A & Field trial & Teleoperation platform \\
{$[17-19]$} & Target recognition & Melon & Lab experiments & User confirmation of machine vision \\
{$[20]$} & Harvesting & Citrus & Simulations & Risk-averse collaboration \\
{$[21]$} & Transportation & N/A & Field trial & Activity recognition \\
{$[22]$} & Human detection & N/A & Field trial & Stereo vision \\
{$[23]$} & Spraying & Vineyard & Field trial & User confirmation of machine vision \\
{$[24,25]$} & Harvesting & Strawberry & Simulation & User confirmation of machine vision \\
{$[26]$} & Harvesting & N/A & Lab experiments & Layered task selection \\
{$[27]$} & Spraying & Canola & Simulation and field trial & Skills transfer interface \\
{$[28]$} & Harvesting & Tea & Field trial & Motion coordination \\
{$[29]$} & N/A & N/A & Correlational study & Acceptance issues \\
{$[30]$} & N/A & N/A & Design principles & Safety issues \\
{$[31]$} & N/A & N/A & Design principles & Safety and ergonomics issues \\
{$[32]$} & Transportation & Strawberry & Field trial & Safety issues \\
\hline
\end{tabular}

In conclusion, from the perspective of human-robot cooperation, it can be seen that the research has focused on two main areas: firstly, for improving the sensory limitations of current vision-based systems. In this context, the human operator complements the automatic detection capabilities of the autonomously navigating robot, by performing an additional verification and corrections of the robot perceptions; secondly, robotic support of manual labor. Here, the robot acts as an assistant to alleviate the burden of arduous and possibly hazardous tasks. In both of these areas, the level of autonomy of the robot and the division of labor between the human and the robot is an open question. This balance is dependent upon the nature of the task at hand, since the effectiveness, efficiency, and accuracy of the robot varies for each function. Additionally, issues that are currently being considered are the design of appropriate human-robot interfaces and ensuring the safety of the human when he shares a common workspace with the robot.

\subsection{UAV Robot Teams (Multi-UAV)}

While UAVs have been used in various tasks in agriculture such as remote sensing (e.g., [33,34]), mapping (e.g., [35]), monitoring (e.g., [36]), and pest control (e.g., [37]), using a single UAV for these tasks presents certain limitations, most prominently time efficiency and battery limitations [38]. First, the time required for a single vehicle to cover a large area can be long. Second, because of the increased task duration and the workload, the energy requirements can force the UAV to cover only a small area between frequent recharges. A solution is to use a team of cooperating UAVs so that the task is divided between different UAVs, which can coordinate their movements by partitioning the area and therefore the workload. Such an approach certainly reduces the task duration but it can also reduce the 
energy consumption at the individual UAV level. Because of the nature of the agricultural work that can be assigned to UAVs, the research in this area is focused on formation control and area coverage algorithms. Even though numerous such algorithms have been developed in the past for a variety of applications, in this section, the focus is specifically on agricultural applications. A recent detailed historical survey of the research in unmanned aerial vehicles in agriculture can be found in [39]. Furthermore, a formal description of managing a group of heterogeneous UAVs was proposed in [40], where parameters such as the field, various facilities, available resources, and constraints were considered.

In 2008, a multi-UAV system for water management and irrigation control was presented [41]. The system is viewed as a camera array with image reconstruction (stitching), and the bands of the images that are collected can be reconfigured depending on the mission. To ensure that the maximum number of images is acquired simultaneously, the system employs formation control where the UAVs are aligned horizontally with a certain distance in between. The paths are precomputed based on mission parameters.

The Swarm Robotics for Agricultural Applications (SAGA) project aims at employing cooperating UAVs for precision farming. In [42], a simulation of the collective behavior of a UAV team for weed monitoring and mapping was presented. The system implements a stochastic coverage and mapping that includes collision avoidance among the aerial vehicles and onboard vision. Further simulation studies on using UAV robot swarms for weed control and mapping were presented in [43]. The monitoring strategy adopted was first to divide the field in cells and assign to each agent a random-walk-based path. The individual agent then decides to move to neighboring cells according to the probability governed by a Gaussian distribution. On the other hand, the Robot Fleets for Highly Effective Agriculture and Forestry Management (RHEA) project aimed at coordinating aerial and ground vehicles in precision agriculture tasks. Specifically, in $[44,45]$, the control structure of the aerial team, consisting of two hex-rotors and tasked with taking high resolution pictures for pest control, was described.

Recall that in [38], the design of a system to perform inspections for precision agriculture by controlling a single UAV or by coordinating multiple UAVs was presented. The system is based on the idea of a control station for on-the-fly mission planning. A heterogeneous embedded framework for small UAVs was also proposed. The work described in [46] involved simulation studies and experiments using four quadrotor aerial vehicles to evaluate a control algorithm for swarm control of agricultural UAV in pest and disease detection. The approach followed in that paper was to implement control in two layers: the first layer was teleoperation where a human operator set the velocity control and the second layer dealt with velocity and formation control as well as collision avoidance. The work in [47] dealt with a surveying task where the UAV team was controlled by a system responsible for connecting the UAVs to act as a swarm, produce flight plans, and respond to disruptive circumstances. Initially, the system divides the survey area in squares, whose size varies according to the UAV's on-board camera characteristics. Each UAV tries to find unvisited and unplanned squares and plans routes depending on both how long a square has remained without supervision and the distance of the UAV to that square. The sub-tasks selected by the UAVs can be exchanged dynamically depending on the predicted sub-task completion times communicated between the agents. A remote sensing task with a self-organizing multi-UAV team capturing georeferenced pictures was presented in [48]. A central controller divided the global task (i.e., the farm area) into sub-tasks and assigned the sub-tasks to the UAVs, based on an extension of the alternate-offers protocol. The UAVs then computed their paths. The proposed approach was validated through field experiments. Similarly, [49] proposed a task allocation and coordination strategy based on a space-based middleware. First, an area decomposition algorithm partitioned the search space so that tasks were dynamically allocated to the UAVs aiming at minimal spatial interference between the UAVs. Second, the task selection was improved by using a model of robot capabilities to extend the space-based middleware. The approach was tested on a weed control task. Another study on a remote sensing task in [50] compared four configu- 
rations of agricultural UAVs, namely autonomous versus teleoperated single and multiple UAV teams. This was essentially an area coverage task. To evaluate the performance of the system, total time, setup time, flight time, battery consumption, inaccuracy of land, haptic control effort, and coverage ratio were used as metrics. Experimental results showed that using the autonomous swarm control algorithm [51] improved the efficiency of the agricultural task.

Another path planning technique for UAV teams was proposed in [52]. In particular, the authors proposed a technique where coordinate transformations between virtual and actual workspaces were performed in order to focus on regions of interest, with conventional path planning algorithms applied to each region. The methods were demonstrated in real-world experiments using $3 \mathrm{UAVs}$ in a surveying task. Table 2 summarizes the basic features of the reviewed studies.

Table 2. Summary of the reviewed multi-UAV cooperation studies in agriculture.

\begin{tabular}{|c|c|c|c|c|c|}
\hline Ref. & Task & Objective & Type of Study & Robot Team & Cooperation Strategy \\
\hline$[40]$ & $\mathrm{N} / \mathrm{A}$ & $\mathrm{N} / \mathrm{A}$ & Formal description & $\begin{array}{c}\text { Variable number of } \\
\text { UAVs }\end{array}$ & $\mathrm{N} / \mathrm{A}$ \\
\hline [41] & $\begin{array}{l}\text { Irrigation } \\
\text { control }\end{array}$ & $\mathrm{N} / \mathrm{A}$ & Field tests & $\begin{array}{c}\text { Variable number of } \\
\text { UAVs }\end{array}$ & Coverage control \\
\hline [42] & Weed mapping & $\mathrm{N} / \mathrm{A}$ & Simulation & $\begin{array}{c}\text { Variable number of } \\
\text { UAVs }\end{array}$ & Coverage control \\
\hline [43] & $\begin{array}{c}\text { Field } \\
\text { monitoring }\end{array}$ & $\mathrm{N} / \mathrm{A}$ & Simulation & $\begin{array}{l}\text { Variable number of } \\
\text { UAVs }\end{array}$ & Individual random walk \\
\hline$[44,45]$ & Pest control & Maize & Architecture design & $\mathrm{N} / \mathrm{A}$ & Central robot management system \\
\hline [46] & $\begin{array}{l}\text { Disease } \\
\text { detection }\end{array}$ & $\mathrm{N} / \mathrm{A}$ & Simulation & Four UAVs & Formation control \\
\hline [47] & Surveying & $\mathrm{N} / \mathrm{A}$ & $\begin{array}{l}\text { Simulation and field } \\
\text { tests }\end{array}$ & Up to $10 \mathrm{UAVs}$ & Distributed mission planning \\
\hline [48] & Mapping & Vineyard & Field tests & Three UAVs & Centralized path planning \\
\hline [49] & Weed control & N/A & Simulation & Three UAVs & Centralized area decomposition \\
\hline [50] & $\mathrm{N} / \mathrm{A}$ & $\mathrm{N} / \mathrm{A}$ & Field tests & Three UAVs & Formation control \\
\hline [51] & $\begin{array}{l}\text { Remote } \\
\text { sensing }\end{array}$ & $\mathrm{N} / \mathrm{A}$ & Simulation & Four UAVs & Formation control \\
\hline [52] & $\begin{array}{l}\text { Crop health } \\
\text { surveying }\end{array}$ & $\mathrm{N} / \mathrm{A}$ & $\begin{array}{c}\text { Simulation and field } \\
\text { tests }\end{array}$ & Three UAVs & Centralized path planning \\
\hline
\end{tabular}

In conclusion, the type of cooperation between artificial systems depends on the characteristics of the cooperating systems. Unmanned aerial vehicles are not normally tasked with physically acting on a field, such as performing seeding or harvesting. In most cases, UAVs are typically equipped with a variety of cameras and sensors and are used for monitoring, pest detection, and mapping. The use of multiple UAVs aims at achieving more rapid field coverage compared to employing a single UAV, and cooperative algorithms aim at improving the efficiency of coverage. In addition, by reducing the task duration, battery limitations of aerial vehicles can be remedied. Consequently, research in this field has mainly focused on path planning and coordination and collision avoidance algorithms which take into account the spatial arrangement and the battery limitations of UAVs. As more technological tools become available, future research will focus on extending the utility of UAVs by improving their perception capabilities and battery autonomy as well as enhancing manipulation skills. Figure 2 shows examples of multi-UAV robot teams. 


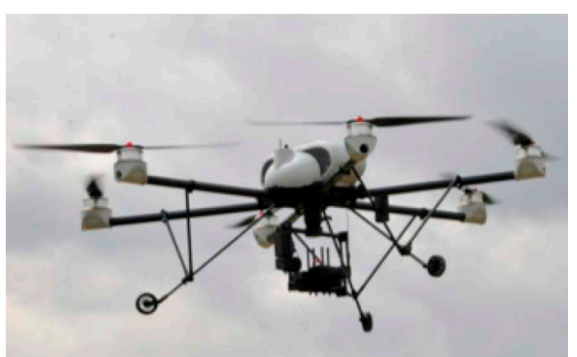

(a) RHEA drone [44]

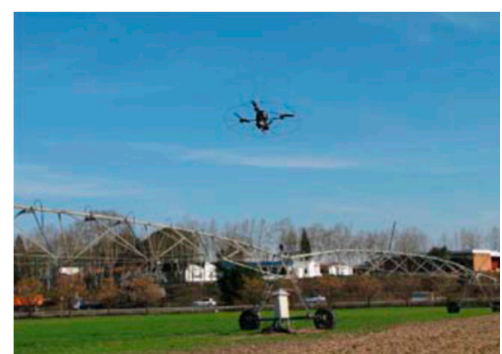

(b) Remote sensing drone [48]

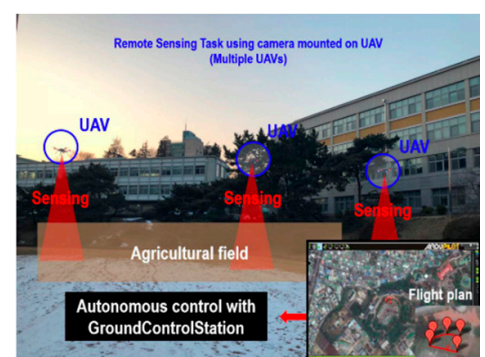

(c) Autonomous multi-UAVs [50]

Figure 2. Examples of multi-UAV cooperative systems.

\subsection{UGV Robot Teams (Multi-UGV)}

An important consideration in using multiple robots in farming operations is to maximize the efficiency and therefore the operational costs. This is achieved by effective task planning and path optimization. In [53], the effect of employing a controlled traffic strategy for a pair of agricultural robots compared to uncontrolled traffic was investigated. The simulation study assumed that one robot was an application unit while the other was a refilling unit. In various scenarios and field traffic patterns, the results showed an efficiency improvement in terms of total distance travelled when traffic control was adopted.

One of the early works in multi-robot control in agricultural robotics was presented in [54]. In that work, two algorithms for the control of two master-slave agricultural robots, namely the GOTO algorithm and a FOLLOW algorithm, were introduced. In the proposed architecture, the master is making decisions and sends commands to the slave vehicle, while the slave vehicle follows the master vehicle and broadcasts its status. Another leader-follower system for agricultural applications was demonstrated in simulation and field tests in $[55,56]$. The robot tractors in this system can work independently, and work cooperatively in the sense that they must keep a certain spatial arrangement during operation. Efficiency improvements were shown when the robots coordinated in either a formation maintenance strategy or a skipping path turn method. Each of the proposed algorithms is suitable for different field operations. In another study [57], the authors discussed a complete farming system which comprised multiple tractors coordinated by a robot management system and central monitoring.

A large part of the work carried out regarding cooperative UGVs in agriculture has been carried out using simulations in order to establish appropriate path planning algorithms. For example, in [58], a simulation of cooperative citrus harvesting was presented. The focus of that study was the demonstration of both a hierarchical task assignment and a trajectory planning algorithm. In the proposed planning framework, there were two main optimization iterations: the cooperative level for formation planning and the individual level for trajectory planning. A leader-follower structure was adopted for the group of agricultural robots. When a configuration trigger event was detected, a wavefront path planning algorithm is used to find an obstacle-free corridor by the leader. The leader then determines the optimal trajectory information and sends it to the followers who, in turn, determine their own local optimal trajectory. The simulation results indicated that the proposed approach is not computationally intensive and can produce optimal paths fast, even though the complex dynamics of the robots are included in the trajectory calculations. The framework is partly decentralized in the sense that some of the computational tasks are decentralized while others are not. The route planner for herbicide applications proposed in [59] considers various criteria in determining the robot teams' routes, including the distance to be travelled, herbicide tank capacity, dynamic characteristics of the heterogeneous robots, etc. A simulation study aimed at studying the planner under different optimization targets (e.g., time to completion) as well as under different conditions (e.g., number of vehicles).

The "Mobile Agricultural Robot Swarms" (MARS) project [60] aimed at employing cooperating small-sized UGVs for precision farming. The work presented in [60] demon- 
strated a system architecture where a centralized controller (OptiVisor) coordinated and supervised the motion of a team of low-level intelligence robot team in a field seeding task. A decentralized swarm control system for various farming operations such as ploughing, seeding, watering, etc. was proposed in [61]. The experiments were conducted in a land area replicating a farm using miniature prototype robots equipped with tools to perform farming operations. The work presented in [62] dealt with a spraying task by a team of robots using local information only. Simulations were utilized to demonstrate the proposed strategy's capacity to perform task allocation. The authors also explored the multi-robot ploughing task in [63]. Also focusing on spraying tasks, specifically for vineyards, the work described in [64] aimed at utilizing at least two robots working on either side of a vine row in order to improve accuracy. For this, the authors employed Ultra-Wide Band (UWB) sensors to achieve relative localization and synchronize the trajectories of the two robots in a leader-follower scheme.

A route planning algorithm for efficient field coverage was proposed in [65]. The objective of this work was to replace multiple large agricultural machinery with smaller autonomous robots in order to minimize soil compaction. The route planning algorithm was designed to produce efficient field coverage for finding routes with minimal costs. The framework included a mission control center to allocate sub-tasks to robot teams, to coordinate their movements, and to allow them to communicate with one another. In a simulation study [66], the authors considered teams of heterogeneous robots (harvesting and transport robots) deployed in grapevines and modeled their behavior in order to investigate the effect of team size in both harvesting and processing times.

The simulation environment named "Simulation Environment for Precision Agriculture Tasks using Robot Fleets" (SEARFS) presented in [67] allows for the investigation of multi-robot teams in precision agriculture and more specifically in a weed management task. It is a general-purpose computational tool that can model a 3D virtual agricultural environment and simulate the behavior of fleets of autonomous agricultural robots. The user is allowed to select the robots, their sensory and actuation characteristics, the type of field, and determine the specific mission. The behavior of the robot fleet can then be studied.

The cooperative two-robot system for rice harvesting proposed in [68] employs two head-feeding combines. To initialize the harvest, a human operator drives the combines a few laps of crops first, in a spiral toward the center of the field. The combines then begin harvesting autonomously according to target paths planned from the locus of the combine while the operator was driving. The robots harvest in a spiral where the second robot is located $1.2 \mathrm{~m}$ inward. Collision avoidance is achieved by inter-robot communication of location.

A simulation of a precision agriculture scenario was presented in [69]. The scenario explores the use of three types of robot for collecting information, sowing, and harvesting. The work focuses on (a) modeling of the robots, which is based on the open-source packages Gazebo and ROS, and (b) interaction between the robots, which is based on the smart space combined with the blockchain platform for information (represented by fuzzy sets) exchange between the robots.

In [70], a monitoring application for precision agriculture using heterogeneous ground robots was presented. The approach followed was to use a weighted directed graph to represent the robot team. The partitioning of the workspace took into account the possible heterogeneous characteristics of the robots such as speed and processing power. According to these characteristics, the robots were distributed on the virtual graph and tasked to monitor a specific region. The potential of the method was demonstrated both by simulations and by experiments on the field.

A collaborative fleet management system for coordinating the flow of operations in a field was demonstrated in simulation and field experiments in [71]. The system supports all the operating stages of a field crop and is based on a novel algorithm which assigns strips of field to each robot, then dynamically updates the state of each strip.

Figure 3 shows examples of multi-UGV robot teams. 


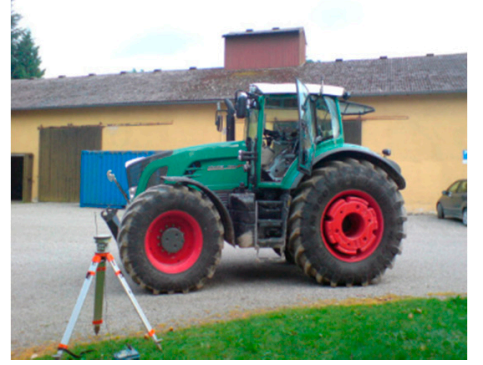

(a) Tractor in leader-follower team [55]

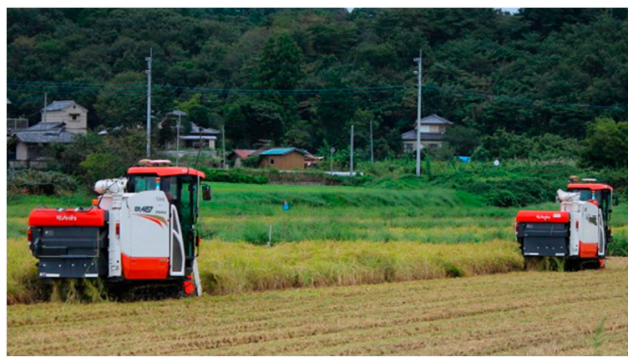

(b) Combine robots [68]

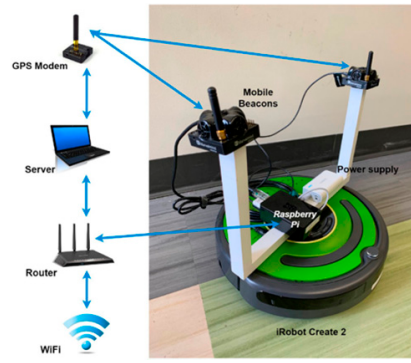

(c) Monitoring robot [70]

Figure 3. Examples of multi-UGV cooperative systems.

Workspace partitioning for a multi-robot system operating in an orchard in a spraying task was the subject of [72]. In this work, given a map induced from a UAV-acquired image, a number of nodes for a Voronoi diagram were produced, where an orchard tree was considered to be a node. The nodes were then clustered so that partitions were computed through the Voronoi diagram. In this case, the robots were not cooperating directly; instead, indirect cooperation arose by coordination of their independent actions. Table 3 summarizes the basic features of the reviewed studies.

Table 3. Summary of the reviewed multi-UGV cooperation studies in agriculture.

\begin{tabular}{|c|c|c|c|c|c|}
\hline Ref. & Task & Objective & Type of Study & Robot Team & Cooperation Strategy \\
\hline [53] & $\mathrm{N} / \mathrm{A}$ & $\mathrm{N} / \mathrm{A}$ & Simulation & $\begin{array}{l}\text { An application unit and a } \\
\text { refilling unit }\end{array}$ & Leader-follower \\
\hline$[54]$ & $\mathrm{N} / \mathrm{A}$ & $\mathrm{N} / \mathrm{A}$ & Simulation & A master and a slave vehicle & Master-slave \\
\hline$[55,56]$ & $\mathrm{N} / \mathrm{A}$ & $\mathrm{N} / \mathrm{A}$ & Field trials & A master and a slave tractor & Master-slave \\
\hline [57] & $\begin{array}{l}\text { Planting, seeding, } \\
\text { transplanting, and } \\
\text { harvesting }\end{array}$ & Rice & $\begin{array}{l}\text { Architecture } \\
\text { design }\end{array}$ & $\begin{array}{l}\text { A robot for data acquisition } \\
\text { and two robot tractors for } \\
\text { farming operations }\end{array}$ & $\begin{array}{c}\text { Central robot } \\
\text { management system }\end{array}$ \\
\hline [58] & Harvesting & Citrus & Simulation & $\begin{array}{l}\text { A virtual leader robot and } \\
\text { three follower robots }\end{array}$ & $\begin{array}{c}\text { Formation selection or } \\
\text { individual trajectory } \\
\text { selection }\end{array}$ \\
\hline [59] & Herbicide application & $\mathrm{N} / \mathrm{A}$ & Simulation & $\begin{array}{l}\text { Multiple } \\
\text { heterogeneous robots }\end{array}$ & Route planning \\
\hline$[60]$ & Seeding & $\mathrm{N} / \mathrm{A}$ & $\begin{array}{l}\text { Simulation and } \\
\text { field tests }\end{array}$ & Variable number of robots & $\begin{array}{c}\text { Central robot } \\
\text { management system }\end{array}$ \\
\hline [61] & $\begin{array}{l}\text { Ploughing, irrigation, } \\
\text { seeding, and } \\
\text { harvesting }\end{array}$ & $\mathrm{N} / \mathrm{A}$ & Lab experiments & $\begin{array}{c}\text { Multiple } \\
\text { heterogeneous robots }\end{array}$ & $\begin{array}{l}\text { Central robot } \\
\text { management system }\end{array}$ \\
\hline$[62,63]$ & Spraying, ploughing & $\mathrm{N} / \mathrm{A}$ & Simulation & Variable number of robots & $\begin{array}{l}\text { Use of information } \\
\text { stored at checkpoints }\end{array}$ \\
\hline$[64]$ & Spraying & $\mathrm{N} / \mathrm{A}$ & Lab experiments & $\begin{array}{l}\text { A leader robot and a } \\
\text { follower robot }\end{array}$ & Formation control \\
\hline [65] & $\mathrm{N} / \mathrm{A}$ & $\mathrm{N} / \mathrm{A}$ & Simulation & Variable number of robots & $\begin{array}{c}\text { Central robot } \\
\text { management system }\end{array}$ \\
\hline [66] & Harvesting, transport & Grapes & Simulation & $\begin{array}{l}\text { One harvesting robot and } \\
\text { two transport robots }\end{array}$ & $\begin{array}{l}\text { Central robot } \\
\text { management system }\end{array}$ \\
\hline [67] & Weed management & $\mathrm{N} / \mathrm{A}$ & Simulation & Variable number of robots & $\begin{array}{c}\text { Central robot } \\
\text { management system }\end{array}$ \\
\hline [68] & Harvesting & Rice & Field trials & Two combine robots & Leader-follower \\
\hline [69] & Harvesting & $\mathrm{N} / \mathrm{A}$ & Simulation & $\begin{array}{l}\text { Variable number of } \\
\text { heterogeneous robots }\end{array}$ & $\begin{array}{c}\text { Central robot } \\
\text { management system }\end{array}$ \\
\hline [70] & Monitoring & $\mathrm{N} / \mathrm{A}$ & $\begin{array}{l}\text { Simulation and } \\
\text { field trials }\end{array}$ & Two robots & Route planning \\
\hline [71] & Coordination & $\mathrm{N} / \mathrm{A}$ & $\begin{array}{l}\text { Simulation and } \\
\text { field trials }\end{array}$ & Three robot tractors & $\begin{array}{c}\text { Central robot } \\
\text { management system }\end{array}$ \\
\hline [72] & Spraying & $\mathrm{N} / \mathrm{A}$ & $\begin{array}{l}\text { Simulation with } \\
\text { real data }\end{array}$ & 2 to 10 robots & $\begin{array}{c}\text { Central robot } \\
\text { management system }\end{array}$ \\
\hline
\end{tabular}


In conclusion, in contrast to UAV systems, UGVs are more suitable for agricultural tasks traditionally demanding human intervention, such as sowing, weeding, spraying, harvesting, etc. Research in this area has focused on improving the efficiency of the aforementioned tasks by introducing multi-robot teams in the field. The introduction of multiple robots in a given area, however, demands appropriate management of the spatial allocation of robots, with several approaches proposed, some stemming from the sub-field of swarm robotics. In the special case of heterogeneous robots assigned with different operations, temporal task allocation is also required. A popular method in the literature is the leader-follower approach, with inter-robot communications coordinating motions based on progress status. More research is required to improve collaborative tasks by ground robots, e.g., transfer of a load between a harvesting and a carrier robot or individual robots harvesting a tree concurrently.

\subsection{UGV and UAV Teams (UAV/UGV)}

While the use of multiple UAVs has advantages such as large area coverage, speed etc., they also have limitations including uncertainty in ground measurements and power limitations. Typically, UAVs are equipped with long-range measuring equipment, such as cameras, and are used in field monitoring tasks. In contrast, UGVs can be deployed in the field to locate targets and either take short-range measurements or perform a physical action. The combined use of UAV and UGV teams has also been proposed in order for the robots to complement each other in agricultural tasks [73].

In [74], the team consisted of a UAV and a UGV for disease detection in a strawberry field. The role of the UAV was to inspect the entire crop and to mark suspect regions. The UGV then approached the marked regions to perform spectral analysis and collect samples.

The robot team presented in [75] consisted of a single UAV and a single UGV. The UGV measured nitrogen in a field, and depending on these measurements, deployed the UAV at selected locations. The UAV landed on the UGV once its mission was complete. This approach has the advantage of limiting the operating time of the UAV, which is desirable given the UAV's limited battery life. The problem is then to minimize the time the UGV needs to obtain soil samples and a path planning algorithm was proposed to this end. The methodology was validated through simulation studies with real-world data.

A bioinspired path planning strategy for coordinating a hybrid (aerial and groundbased) multi-robot team toward a target was presented in [76]. In this strategy, investigated using simulation studies, the three=dimensional terrain was modeled as a neuron topological map and a Dragonfly Algorithm (DA) optimized the movements of the robots. Although this algorithm was not developed specifically for agriculture, the scenario can have applications in agricultural robot teams consisting of UAVs and UGVs. Other examples of $\mathrm{UAV} / \mathrm{UGV}$ coordination approaches can be found in [77-79].

As mentioned earlier, the RHEA project dealt with coordinating aerial and ground robots in precision agriculture [80,81]. In [81], two sub-tasks of weed and pest control missions were considered: (a) inspection missions carried out by the aerial team and (b) treatment missions carried out by the ground robots. A Mission Manager was employed to manage the collected data from the various units and centrally compute the trajectories and actions of the robots. Furthermore, the ground robot plans were optimized based on factors such as costs and time.

In $[82,83]$, a UGV and UAV independently generated point clouds that represented a map of a field using own on-board cameras. The proposed methodology aimed at effectively merging the two individual maps, thus producing a more accurate map which included the surface model as well as the vegetation index. Therefore, collaboration was implicit and arose from the aggregate result of the individual measurements.

In $[84,85]$, dual agricultural robot teams consisting of an aerial unit and a ground unit were proposed, but no details on the implementation of the proposed cooperation strategy were given. Similarly, the hardware design of a dual UAV/UGV robot system 
was proposed in [86]. The objective of the system was to collect images of a crop and then process them using various vegetation indices in order to determine the crop status.

Another approach for robot team control was followed in another simulation study [87], where the agricultural robot team consisted of three unmanned aerial vehicles and one unmanned ground robot. Each robot was modeled as a finite state automaton and the entire multi-robot system as a discrete event system. It featured a supervisory controller that enabled heterogeneous agricultural robots to perform field operations, avoid obstacles, follow a defined formation, and follow a given path. Table 4 summarizes the basic characteristics of the reviewed studies. Figure 4 shows examples of UAV/UGV robot teams.

Table 4. Summary of the reviewed UAV/UGV cooperation studies in agriculture.

\begin{tabular}{|c|c|c|c|c|c|}
\hline Ref. & Task & Objective & Type of Study & Robot Team & Cooperation Strategy \\
\hline [74] & Disease detection & Strawberry & Architecture design & One UAV and one UGV & $\begin{array}{l}\text { UGV visiting locations } \\
\text { identified by the UAV }\end{array}$ \\
\hline$[75]$ & Fertilization & Not specified & Simulation & One UAV and one UGV & $\begin{array}{l}\text { UGV visiting locations } \\
\text { identified by the UAV }\end{array}$ \\
\hline$[80,81]$ & Pest control & Winter cereal & Field trials & $\begin{array}{c}\text { Two six-rotor drones and } \\
\text { three tractors }\end{array}$ & $\begin{array}{l}\text { UGVs visiting locations } \\
\text { identified by the UAVs }\end{array}$ \\
\hline$[82,83]$ & Mapping & Not specified & Simulation with real data & $\begin{array}{l}\text { One UAV and one } \\
\text { simulated UGV }\end{array}$ & Map data fusion \\
\hline [84] & Crop management & Lettuce & Architecture design & One UAV and one UGV & $\begin{array}{l}\text { UGV visiting locations } \\
\text { identified by the UAV }\end{array}$ \\
\hline [85] & Inspection & Not specified & Architecture design & One UAV and one UGV & $\begin{array}{c}\text { Transportation of UAV by } \\
\text { the UGV }\end{array}$ \\
\hline [86] & Crop status mapping & Not specified & Architecture design & One UAV and one UGV & Crop data fusion \\
\hline [87] & $\mathrm{N} / \mathrm{A}$ & $\mathrm{N} / \mathrm{A}$ & Simulation & $\begin{array}{c}\text { Three UAVs and } \\
\text { one UGV }\end{array}$ & $\begin{array}{l}\text { Leader-follower } \\
\text { formation control }\end{array}$ \\
\hline
\end{tabular}

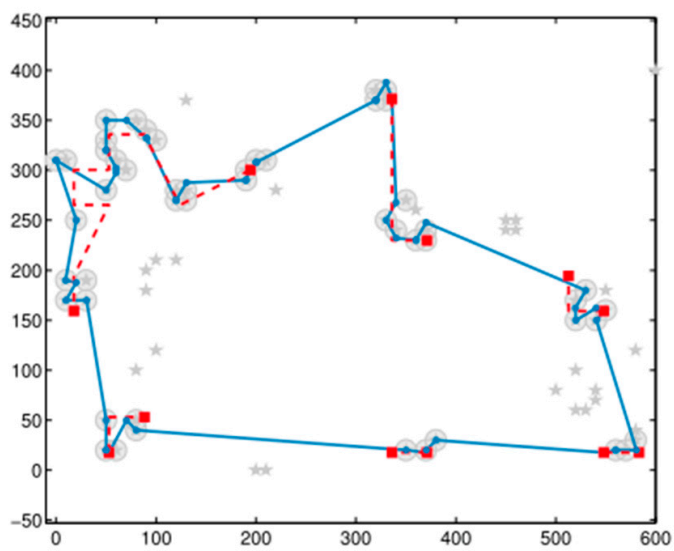

(a) Simulation of a UAV and a UGV visiting points in a field [75]

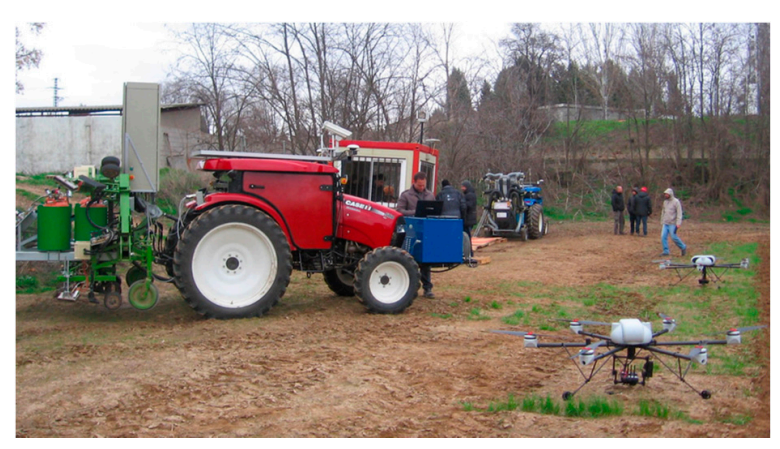

(b) RHEA UAV/UGV fleet [81]

Figure 4. Examples of UAV/UGV cooperative system.

In summary, hybrid robot teams comprised of UAVs and UGVs engaged in agricultural work are found in the literature, exploiting their relative merits. In particular, the aerial vehicle(s) first mark areas of interest and then the ground robot approaches the location and performs the necessary operations. Another cooperation strategy between the UAV and the UGV in the literature is that the UGVs can also serve as landing and charging stations for the accompanying aerial vehicle.

\subsection{Cooperative Manipulation (Manipulators)}

The notion of cooperative operation in agricultural robots can also be extended from cooperation between separate robotic platforms to cooperation between arms typically mounted on the same robot. The main benefit of a multi-arm robotic system performing an agricultural task is to improve efficiency and reduce the task duration. In addition, the arms can be actively collaborating toward the same goal, e.g., both working together 
to harvest a single fruit, therefore attempting to solve problems such as occlusion. The principles governing cooperative manipulation by robotic arms mounted on a single robot platform can also be extended to cooperative manipulation by robotic arms mounted on separate robotic platforms.

A multi-arm kiwi harvester was presented in [88]. The system was equipped with four identical 3 Degrees-of-Freedom (DoF) arms with customized grippers. Although the arms harvested the fruit independently, there was an overall task scheduler which, based on the detected fruits, created fruit clusters, determined the harvesting order, and assigned fruit clusters to each arm. Another multi-arm robot for melon harvesting was presented in [89]. The proposed system consisted of four Cartesian manipulators which reached down, picked melons, and placed them on lateral conveyors. The assignment of melons to each arm was considered to be an interval graph coloring problem, with a greedy search algorithm that calculated an optimal solution for the harvest order. The controller took into account the kinematic conditions that governed the capabilities of each arm and the hardware design was oriented toward improving the harvest ratio. A dual-arm strawberry harvesting robot was described in [90]. Two single-rail 5 DoF manipulators were controlled by a collision avoidance and harvesting order planner based on the location of detected strawberries. The authors reported reduced harvesting times with the dual-arm robot compared to harvesting with a single manipulator.

Cooperative manipulation in an apple orchard was demonstrated in [91]. The authors employed a graph-based method to guide two 6 DoF arms. Each arm was assigned a different role; the grasping arm was designated to pick the apple and the searching arm was designated to locate apples that were hidden from the point of view of the grasping arm. Both arms were equipped with depth cameras. Location information was encoded as a graph whose nodes could be used to calculate appropriate paths. The study reported that the method worked reasonably well in simulation as well as in experimental studies. Apple harvesting using dual cooperative manipulators was also proposed in [92]. In this case, simulation studies were carried out where RGB cameras, located on the manipulators' end effectors, were assumed to accurately detect and locate apples on randomly generated virtual trees. The two manipulators cooperated since one served as the searching arm which identified the other's (grasping arm's) reference points and helped determine clear paths to the detected fruit.

The dual-arm configuration proposed in [93] for aubergine harvesting assumed three modes of operation: (1) a single arm picking a single aubergine, (2) two arms picking fruits independently, and (3) arms working cooperatively to pick a single aubergine. In the second mode, a planning algorithm was developed for task scheduling and collision avoidance. The cooperative mode was employed when there was limited visibility to a fruit and so, one arm was tasked with removing any occlusions while the other arm was tasked with grasping. The performance of the system was evaluated in laboratory experiments.

In [94], a pair of collaborating manipulators were evaluated in an apple harvesting task. The first manipulator was equipped with an 8-DoF manipulator and was tasked with picking apples, while the second one was a catching manipulator with two links which could reach any drop position in the picking manipulator's workspace. Two strategies of fruit harvesting were tested in studies with a replica apple tree, in order to determine the most efficient method in terms of average picking time. However, additional tests in the field demonstrated the need for additional considerations in the picking strategies in order to limit damage to the harvested fruit.

A robot for harvesting greenhouse tomatoes was described in [95]. Two mirrored 3-DoF arms in this dual-arm system had different end-effectors: one arm was fitted with a cutter and the other one was fitted with a suction cup. A single stereo camera mounted at the top of the robot captured images that were processed by a computer responsible for tomato detection and performed a 3D world reconstruction, after which the arm with the vacuum end effector grasped the fruit while the other arm detached the fruit. A planting and watering dual-arm robot was presented in [96]. The prototype robot was 
equipped with two Prismatic-Revolute (PR) arms which were tasked with digging, seeding, and covering the soil. Then, there was a separate watering module which was activated depending on the readings of a soil moisture sensor. Table 5 summarizes the basic features of the reviewed studies.

Table 5. Summary of the examined cooperative manipulation studies in agriculture.

\begin{tabular}{lccccc}
\hline Ref. & Task & Objective & Type of Study & Mode of Operation & Manipulators \\
\hline$[88]$ & Harvesting & Kiwi & Field trials & Arm coordination & Four 3-DoF arms \\
{$[89]$} & Harvesting & Mellon & Simulation & Arm coordination & Variable number of 3-DoF arms \\
{$[90]$} & Harvesting & Strawberry & Field trials & Arm coordination & Two single-rail 5-DoF arms \\
{$[91]$} & Harvesting & Apple & $\begin{array}{c}\text { Simulation and } \\
\text { lab experiments }\end{array}$ & Arm collaboration & Two 6-DoF arms \\
{$[92]$} & Harvesting & Apple & Simulation & Arm collaboration & Two 6-DoF arms \\
{$[93]$} & Harvesting & Aubergine & Lab experiments & Arm collaboration & Two 6-DoF arms \\
{$[94]$} & Harvesting & Apple & Lab experiments & Arm collaboration & An 8-DOF arm and a 2-DoF arm \\
{$[95]$} & Harvesting & Tomato & Field experiments & Arm collaboration & Two mirrored 3-DoF arms \\
{$[96]$} & Planting and watering & N/A & Field experiments & Arm coordination & Two 2-DoF arms \\
\hline
\end{tabular}

In conclusion, cooperative manipulation for agricultural operations is generally applied by robotic manipulators mounted on the same vehicle in order to collaborative complete a task, mainly harvesting. Although there are several agricultural robots equipped with more than one manipulator, in most cases the robotic arms operate independently with some planning algorithm coordinating motions for task assignment and collision avoidance. Few studies examine actual cooperative manipulation tasks, such as two robotic arms cooperatively picking an individual fruit. These can be especially advantageous in cases where view of fruits is limited due to occlusion or when cutting and grasping of fruit may require two hands. For instance, recently, the European project BACCHUS [97] considered, in a cognitive mechatronics context, the development of a bi-manual robotic platform for grape harvest; detailed application results are expected in the future. Nevertheless, to the authors' knowledge, applications where cooperative manipulation must be performed by arms mounted on different mobile platforms are yet to appear in agricultural robotics, and this is another future direction for research. Such a system would render the robot team more flexible, as one of the platforms could be attending to other field work and assist the other platform only when needed. This would improve the efficiency of the work and would reduce the need for additional task-specific machines, reducing operational costs as a result. The increased complexity and sophistication of such a system could potentially be compensated to some degree by the aforementioned flexibility it would provide.

Figure 5 shows systems with cooperative manipulators.

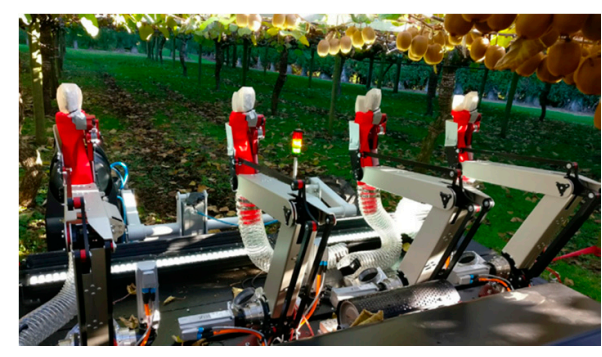

(a) Kiwi harvester [88]

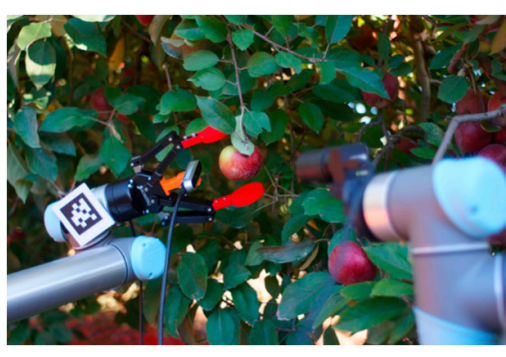

(b) Apple harvesting arms [91]

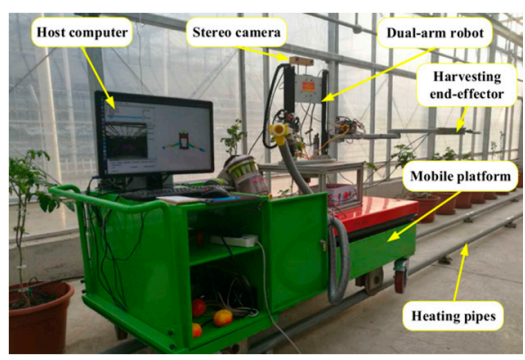

(c) Tomato harvester [95]

Figure 5. Examples of multi-arm systems. 


\subsection{Trends}

With the 77 articles studied in this review, trends were identified in the field of cooperative agricultural robotics. More specifically, the distribution per publication type (i.e., conferences, journals, theses, and books) is shown in the pie chart in Figure 6, which shows that the 77 articles were fairly evenly distributed mainly between conference publications (33) and journal publications (42); in addition, one thesis and one book have been published.

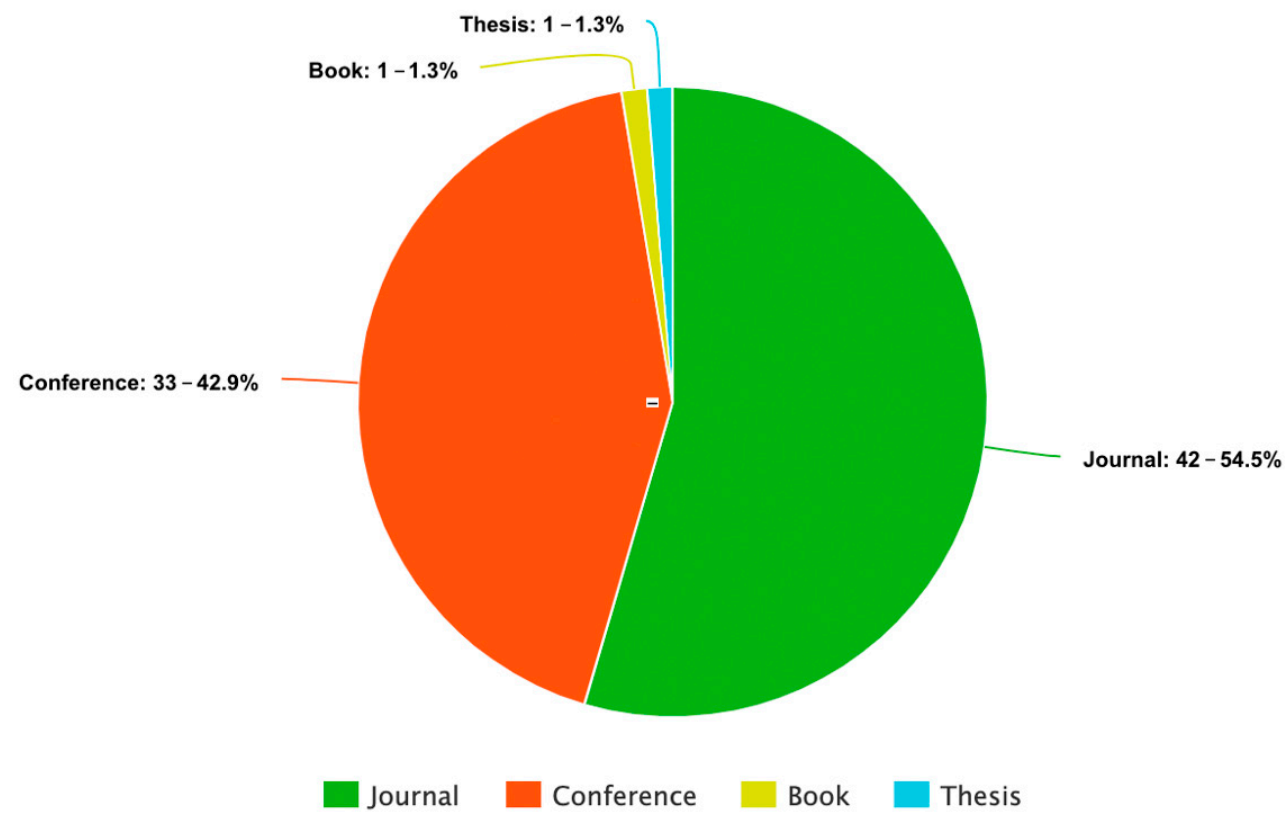

Figure 6. Number of articles per publication type (i.e., conferences, journals, theses, and books).

The pie chart in Figure 7 shows the distribution of the 77 articles in the assumed five sections, namely (a) human-robot, (b) multi-UAV, (c) multi-UGV, (d) UAV/UGV, and (e) manipulators.

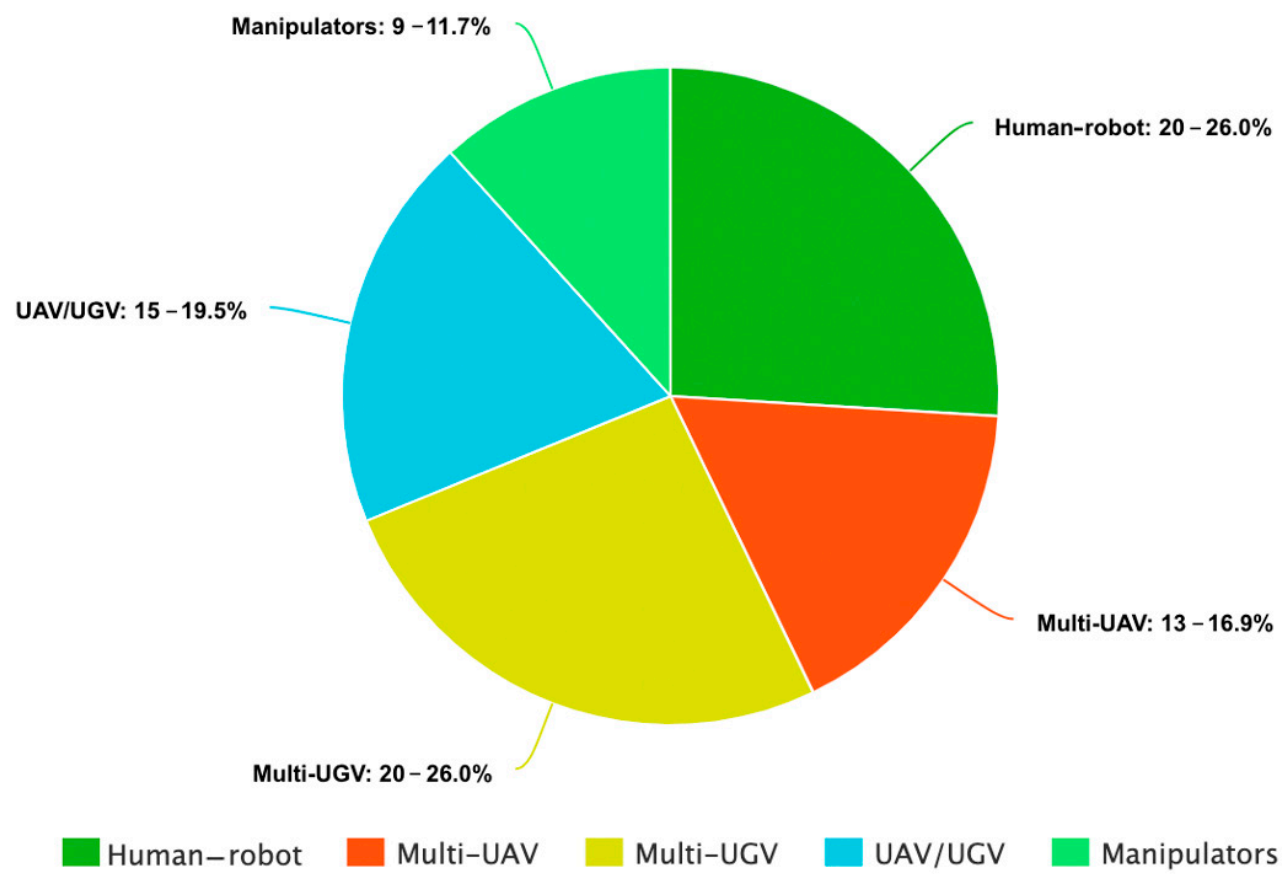

Figure 7. Distribution of articles per topic. 
The bar chart in Figure 8 displays the distribution of the 77 articles in various geographical regions including North America, Asia, Europe, and elsewhere, such that, on the bar of a region, the distribution of different topics is also indicated by different colors. Furthermore, Figure 9 details the distribution of the 77 articles in different countries; again, on the bar of a country, the distribution of different topics is indicated by different colors.

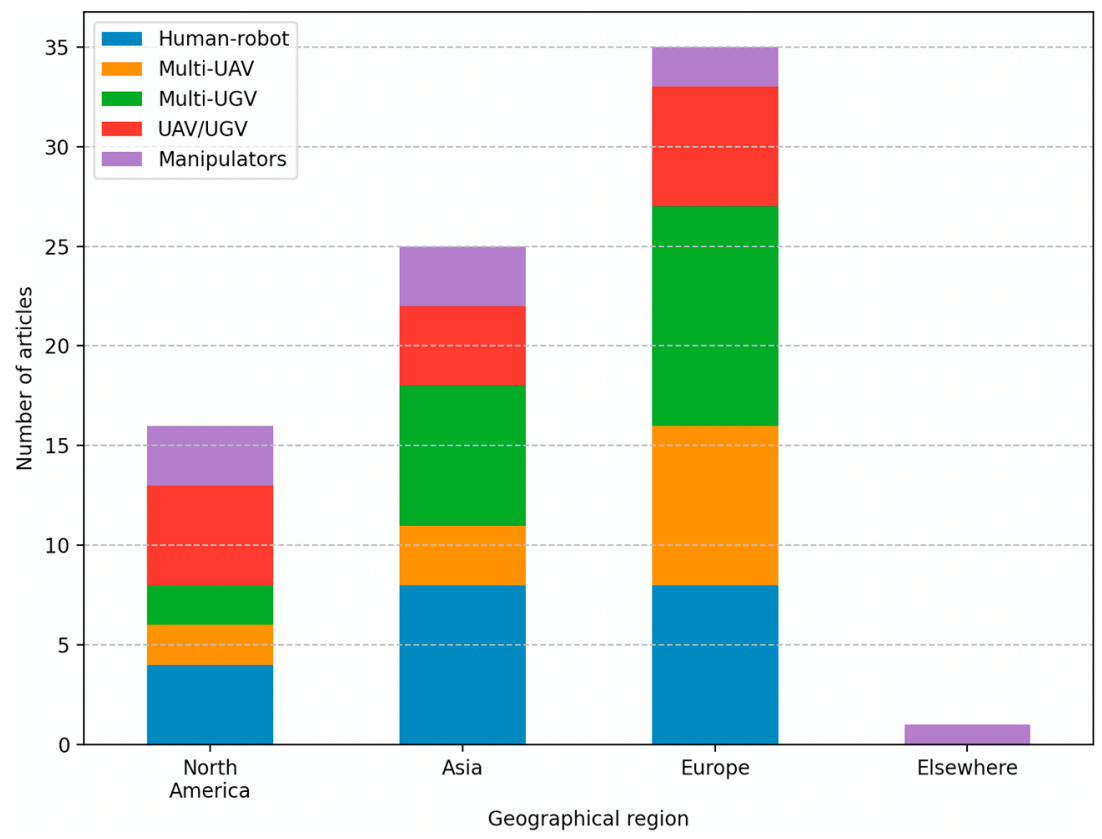

Figure 8. Geographical distribution of articles per geographical region per topic.

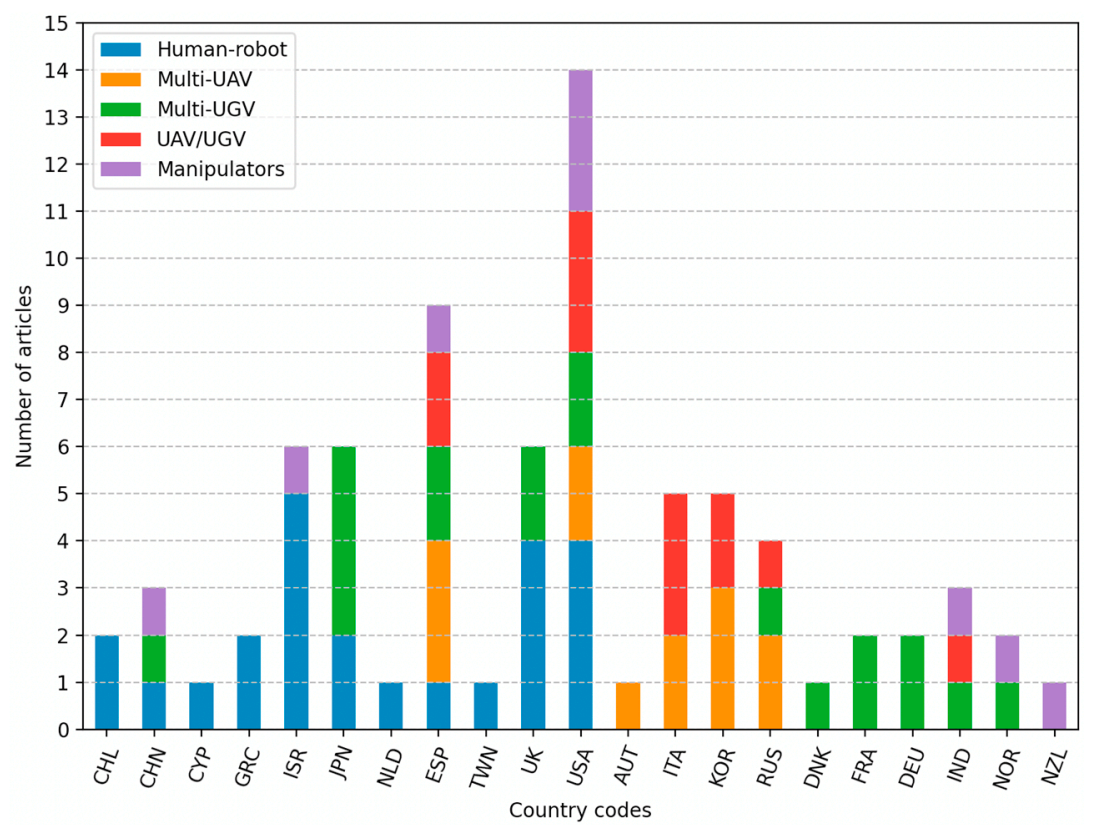

Figure 9. Geographical distribution of articles per country per topic.

Finally, the bar chart in Figure 10 displays the distribution of the 77 articles per year from the year 2003 to the year 2021, where, on the bar of a year, the distribution to different topics is indicated by a different color. An abrupt increase is obvious in Figure 10 in the year 2016. More specifically, since 2016, there has been a sustained increase (tripling or more) of the annual publications compared to the previous years, before 2016. The reason for the aforementioned abrupt increase is unknown. However, for the current year (2021), 
based on evidence, it is reasonable to assume that the aforementioned trend is sustainable because 6 publications have already been reported up to May. In the aforementioned sense, the recent COVID-19 pandemic does not seem to have affected interest in this technology.

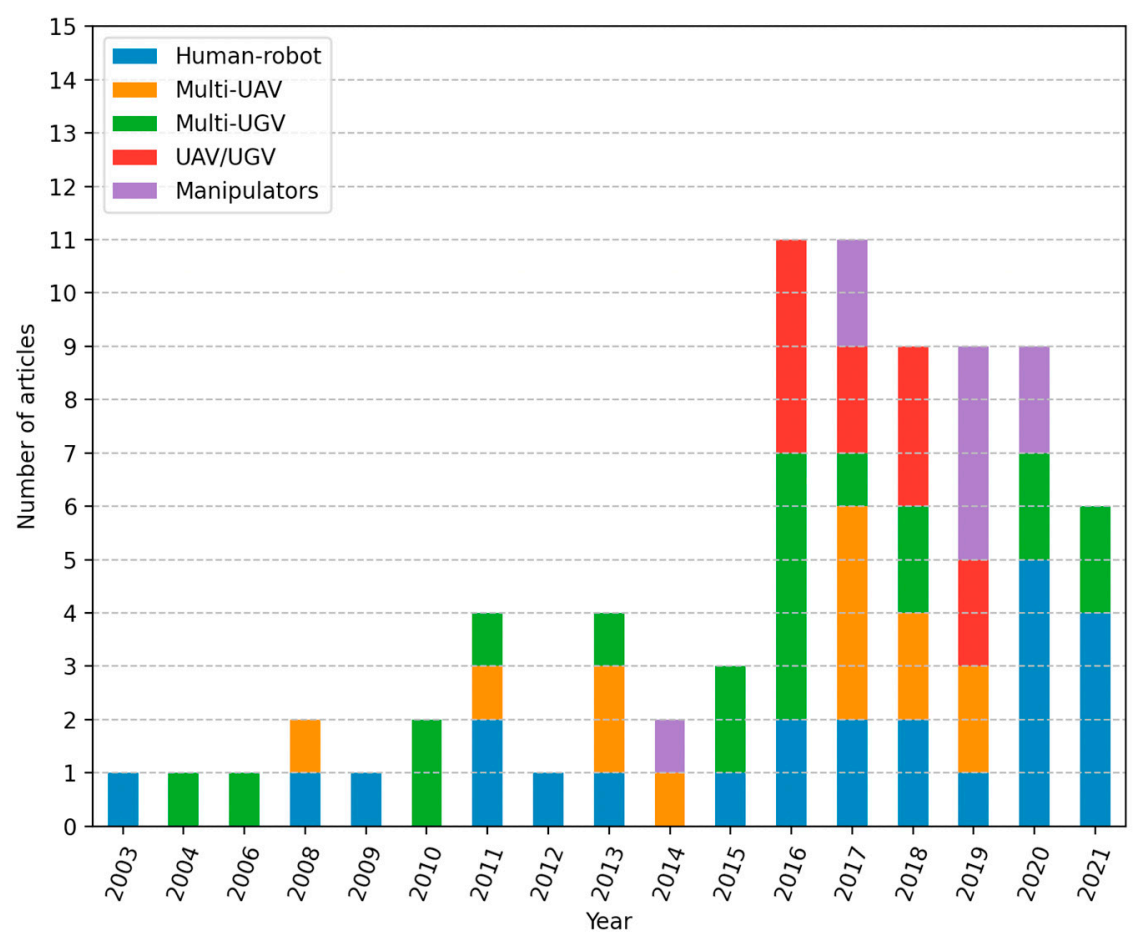

Figure 10. Number of articles in chronological order. The year 2021 was partially included (up to May).

\section{Discussion and Conclusions}

This paper reviewed fifteen years of work on cooperative robotics in agriculture including human-robot and robot-robot cooperation. Five different topics were identified, namely (a) human-robot cooperation (human-robot), (b) cooperative UAVs (multi-UAV), (c) cooperative UGVs (multi-UGV), (d) hybrid teams of UAVs and UGVs (UAV/UGV), and (e) cooperative manipulation by multi-arm systems (manipulators).

The compiled evidence from the literature (Figures 6-9) suggests that there is an emerging global interest in cooperative robotics in agriculture. In conclusion, Figure 10 confirms that the interest in the area has clearly increased over the last 15 years.

There are a number of important reasons for considering cooperative robotics in agriculture. One reason is food production for an increasingly vast human population, especially under seasonal human labor shortages, e.g., during harvest. Another reason is controllably minimal environmental pollution pursued by the minimization of human involvement during food production. Yet another reason is sustainable food production in the event of natural disasters, including climate changes as well as pandemics such as the recent COVID-19 pandemic.

The technology of interest here, namely "collaborative robotics in agriculture", was described as (a) an "Agriculture 4.0" technology, and (b) a precursor to "Agriculture 5.0" technology; the latter regards an integration of humans with robots in agricultural applications.

In the aforementioned context, a significant technological challenge remains, which is the development of models to effectively drive a robot during its interaction with another robot and/or a human. Note that a robot in agriculture has been described as a CyberPhysical System (CPS) [7]. In the latter context, the "Lattice Computing (LC) information processing paradigm" has been proposed as a promising mathematical domain for rigorous modeling CPSs due to LC's capacity to accommodate rigorously both numerical data (regarding the "physical" components of a CPS) and non-numerical data (regarding the 
"cyber" components of a CPS) [98]. Moreover, the work in [7] considered the potential of LC in agricultural applications. Future work remains to demonstrate it further [99].

Based on the reviewed work, a number of research areas in cooperative agricultural robotics are still open to further development in order to improve the current systems, both in terms of usefulness as well as reliability, thus reaching the stage of commercial availability in the near future. In terms of human-robot collaborative teams, it is important to research appropriate interfaces so that effective collaborative control is achieved, especially by field workers with minimal technological training. In addition, human-robot coordination is still a very promising research area that will provide robots with a better perception of human actions and intentions, and therefore greatly improve coordination issues. On the other hand, monitoring tasks require the deployment of large numbers of cooperating aerial and ground vehicles. Despite the increasing availability of affordable small-sized robotic platforms, it appears that the power requirements of such robots are restricting the number of tasks they are able to perform, and, as a result, they are limited to short inspection and mapping missions. Finally, a promising research field is the cooperative manipulation of agricultural products, as applied in harvesting and transportation operations. In addition to being indispensable in some tasks, for instance occlusion removal or handling, the use of multiple arms in a cooperative manner could mitigate limitations of other underlying technologies such as vision.

Figure 11 shows the SWOT analysis of cooperative approaches in agricultural robotics.

\section{Strengths}

- Reduction of task duration

- Completion of tasks where heterogeneous robots are required

- Reduction of soil compaction through the use of smaller machines

- Redundancy in cases of hardware failure

\section{Opportunities}

- Labor shortages of seasonal workers

- Increased availability of lowcost robotic equipment and platforms

\section{Weaknesses}

- Limitations in power autonomy

- Human-robot interfaces and action coordination

- Absence of cooperation between humans and multiple robots

\section{Threats}

Human-robot work safety

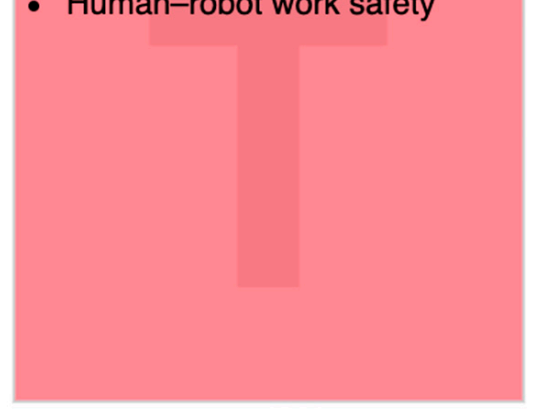

Figure 11. SWOT analysis.

Additional research, in the context of this work, regarded the engagement of collaborative robots for livestock handling. It turned out that only a few publications exist in the literature typically involving single robots. We believe that there is a promising potential in using teams of collaborative robots for livestock handling. 
Author Contributions: Conceptualization, C.L. and V.G.K.; methodology, V.G.K. and T.P.; validation, M.M. and S.C.; formal analysis, C.L., T.P., M.M. and E.V.; writing-original draft preparation, C.L., V.G.K., T.P. and T.K.; writing-review and editing, C.L., T.K., E.V. and S.C.; supervision, V.G.K. All authors have read and agreed to the published version of the manuscript.

Funding: We acknowledge support of this work by the project "Technology for Skillful Viniculture (SVtech)" (MIS 5046047) which is implemented under the Action "Reinforcement of the Research and Innovation Infrastructure" funded by the Operational Program "Competitiveness, Entrepreneurship and Innovation" (NSRF 2014-2020) and co-financed by Greece and the European Union (European Regional Development Fund).

Institutional Review Board Statement: Not applicable.

Informed Consent Statement: Not applicable.

Conflicts of Interest: The authors declare no conflict of interest.

\section{References}

1. Lowenberg-DeBoer, J.; Erickson, B. Setting the Record Straight on Precision Agriculture Adoption. Agron. J. 2019, 111, 1552-1569. [CrossRef]

2. Marinoudi, V.; Sørensen, C.G.; Pearson, S.; Bochtis, D. Robotics and labour in agriculture. A context consideration. Biosyst. Eng. 2019, 184, 111-121. [CrossRef]

3. Bac, C.W.; van Henten, E.J.; Hemming, J.; Edan, Y. Harvesting Robots for High-value Crops: State-of-the-art Review and Challenges Ahead. J. Field Robot. 2014, 31, 888-911. [CrossRef]

4. Fountas, S.; Mylonas, N.; Malounas, I.; Rodias, E.; Hellmann Santos, C.; Pekkeriet, E. Agricultural Robotics for Field Operations. Sensors 2020, 20, 2672. [CrossRef]

5. Oliveira, L.F.P.; Moreira, A.P.; Silva, M.F. Advances in Agriculture Robotics: A State-of-the-Art Review and Challenges Ahead. Robotics 2021, 10, 52. [CrossRef]

6. Skillful Viniculture Technology (SVTECH), Action "Reinforcement of the Research and Innovation Infrastructure", Operational Programme “Competitiveness, Entrepreneurship and Innovation", NSRF (National Strategic Reference Framework) $2014-2020$. Available online: http:/ / evtar.eu/en/home_en/ (accessed on 10 May 2021).

7. Vrochidou, E.; Tziridis, K.; Nikolaou, A.; Kalampokas, T.; Papakostas, G.A.; Pachidis, T.P.; Mamalis, S.; Koundouras, S.; Kaburlasos, V.G. An Autonomous Grape-Harvester Robot: Integrated System Architecture. Electronics 2021, 10, 1056. [CrossRef]

8. Welfare, K.S.; Hallowell, M.R.; Shah, J.A.; Riek, L.D. Consider the Human Work Experience When Integrating Robotics in the Workplace. In Proceedings of the 2019 14th ACM/IEEE International Conference on Human-Robot Interaction (HRI), Daegu, Korea, 11-14 March 2019; pp. 75-84.

9. Vasconez, J.P.; Kantor, G.A.; Auat Cheein, F.A. Human-robot interaction in agriculture: A survey and current challenges. Biosyst. Eng. 2019, 179, 35-48. [CrossRef]

10. Cheein, F.A.; Herrera, D.; Gimenez, J.; Carelli, R.; Torres-Torriti, M.; Rosell-Polo, J.R.; Escola, A.; Arno, J. Human-robot interaction in precision agriculture: Sharing the workspace with service units. In Proceedings of the 2015 IEEE International Conference on Industrial Technology (ICIT), Seville, Spain, 17-19 March 2015; pp. 289-295. [CrossRef]

11. van Henten, E.J.; Bac, C.W.; Hemming, J.; Edan, Y. Robotics in protected cultivation. IFAC Proc. Vol. 2013, 46, 170-177. [CrossRef]

12. Bechar, A.; Vigneault, C. Agricultural robots for field operations: Concepts and components. Biosyst. Eng. 2016, 149, 94-111. [CrossRef]

13. Sheridan, T.B. Human-Robot Interaction. Hum. Factors J. Hum. Factors Ergon. Soc. 2016, 58, 525-532. [CrossRef]

14. Adamides, G.; Katsanos, C.; Constantinou, I.; Christou, G.; Xenos, M.; Hadzilacos, T.; Edan, Y. Design and development of a semi-autonomous agricultural vineyard sprayer: Human-robot interaction aspects. J. Field Robot. 2017, 34, 1407-1426. [CrossRef]

15. Gomez-Gil, J.; San-Jose-Gonzalez, I.; Nicolas-Alonso, L.F.; Alonso-Garcia, S. Steering a Tractor by Means of an EMG-Based Human-Machine Interface. Sensors 2011, 11, 7110-7126. [CrossRef] [PubMed]

16. Murakami, N.; Ito, A.; Will, J.D.; Steffen, M.; Inoue, K.; Kita, K.; Miyaura, S. Development of a teleoperation system for agricultural vehicles. Comput. Electron. Agric. 2008, 63, 81-88. [CrossRef]

17. Bechar, A.; Edan, Y. Human-robot collaboration for improved target recognition of agricultural robots. Ind. Robot Int. J. 2003, 30, 432-436. [CrossRef]

18. Tkach, I.; Bechar, A.; Edan, Y. Switching Between Collaboration Levels in a Human-Robot Target Recognition System. IEEE Trans. Syst. Man Cybern. Part C (Appl. Rev.) 2011, 41, 955-967. [CrossRef]

19. Bechar, A.; Meyer, J.; Edan, Y. An Objective Function to Evaluate Performance of Human-Robot Collaboration in Target Recognition Tasks. IEEE Trans. Syst. Man Cybern. Part C (Appl. Rev.) 2009, 39, 611-620. [CrossRef]

20. Rysz, M.W.; Mehta, S.S. A risk-averse optimization approach to human-robot collaboration in robotic fruit harvesting. Comput. Electron. Agric. 2021, 182, 106018. [CrossRef]

21. Anagnostis, A.; Benos, L.; Tsaopoulos, D.; Tagarakis, A.; Tsolakis, N.; Bochtis, D. Human Activity Recognition through Recurrent Neural Networks for Human-Robot Interaction in Agriculture. Appl. Sci. 2021, 11, 2188. [CrossRef] 
22. Yang, L.; Noguchi, N. Human detection for a robot tractor using omni-directional stereo vision. Comput. Electron. Agric. 2012, 89, 116-125. [CrossRef]

23. Berenstein, R.; Edan, Y. Human-robot collaborative site-specific sprayer. J. Field Robot. 2017, 34, 1519-1530. [CrossRef]

24. Huang, Z.; Miyauchi, G.; Gomez, A.S.; Bird, R.; Kalsi, A.S.; Jansen, C.; Liu, Z.; Parsons, S.; Sklar, E. An Experiment on HumanRobot Interaction in a Simulated Agricultural Task. In Lecture Notes in Computer Science (Including Subseries Lecture Notes in Artificial Intelligence and Lecture Notes in Bioinformatics); Springer: Berlin/Heidelberg, Germany, 2020; Volume 12228 LNAI, pp. 221-233. ISBN 9783030634858.

25. Huang, Z.; Gomez, A.; Bird, R.; Kalsi, A.; Jansen, C.; Liu, Z.; Miyauchi, G.; Parsons, S.; Sklar, E. Understanding human responses to errors in a collaborative human-robot selective harvesting task. In Proceedings of the UKRAS20 Conference: "Robots into the Real World" Proceedings, Lincoln, England, 17 April 2020; EPSRC UK-RAS Network, 2020. pp. 89-91.

26. Kim, M.; Koh, I.; Jeon, H.; Choi, J.; Min, B.C.; Matson, E.T.; Gallagher, J. A HARMS-based heterogeneous human-robot team for gathering and collecting. Adv. Robot. Res. 2018, 3, 201-217. [CrossRef]

27. Zhou, X.; He, J.; Chen, D.; Li, J.; Jiang, C.; Ji, M.; He, M. Human-robot skills transfer interface for UAV-based precision pesticide in dynamic environments. Assem. Autom. 2021, 41, 345-357. [CrossRef]

28. Lai, Y.-L.; Chen, P.-L.; Yen, P.-L. A Human-Robot Cooperative Vehicle for Tea Plucking. In Proceedings of the 20207 th International Conference on Control, Decision and Information Technologies (CoDIT), Prague, Czech Republic, 29 June-2 July 2020; Volume 2, pp. 217-222.

29. Baylis, L.C. Organizational Culture and Trust within Agricultural Human-Robot Teams. Ph.D. Thesis, Grand Canyon University, Phoenix, AZ, USA, 2020.

30. Rose, D.C.; Lyon, J.; de Boon, A.; Hanheide, M.; Pearson, S. Responsible development of autonomous robotics in agriculture. Nat. Food 2021, 2, 306-309. [CrossRef]

31. Benos, L.; Bechar, A.; Bochtis, D. Safety and ergonomics in human-robot interactive agricultural operations. Biosyst. Eng. 2020, 200, 55-72. [CrossRef]

32. Baxter, P.; Cielniak, G.; Hanheide, M.; From, P. Safe Human-Robot Interaction in Agriculture. In Proceedings of the Companion of the 2018 ACM/IEEE International Conference on Human-Robot Interaction, Chicago, IL, USA, 5-8 March 2018; ACM: New York, NY, USA, 2018; pp. 59-60.

33. Alsalam, B.H.Y.; Morton, K.; Campbell, D.; Gonzalez, F. Autonomous UAV with vision based on-board decision making for remote sensing and precision agriculture. In Proceedings of the 2017 IEEE Aerospace Conference, Big Sky, MT, USA, 4-11 March 2017; pp. 1-12.

34. Santesteban, L.G.; Di Gennaro, S.F.; Herrero-Langreo, A.; Miranda, C.; Royo, J.B.; Matese, A. High-resolution UAV-based thermal imaging to estimate the instantaneous and seasonal variability of plant water status within a vineyard. Agric. Water Manag. 2017, 183, 49-59. [CrossRef]

35. Torres-Sánchez, J.; López-Granados, F.; Serrano, N.; Arquero, O.; Peña, J.M. High-throughput 3-D monitoring of agricultural-tree plantations with Unmanned Aerial Vehicle (UAV) technology. PLoS ONE 2015, 10, e0130479. [CrossRef]

36. Long, D.; McCarthy, C.; Jensen, T. Row and water front detection from UAV thermal-infrared imagery for furrow irrigation monitoring. In Proceedings of the 2016 IEEE International Conference on Advanced Intelligent Mechatronics (AIM), Banff, AB, Canada, 12-15 July 2016; pp. 300-305.

37. Faiçal, B.S.; Freitas, H.; Gomes, P.H.; Mano, L.Y.; Pessin, G.; de Carvalho, A.C.P.L.F.; Krishnamachari, B.; Ueyama, J. An adaptive approach for UAV-based pesticide spraying in dynamic environments. Comput. Electron. Agric. 2017, 138, 210-223. [CrossRef]

38. Doering, D.; Benenmann, A.; Lerm, R.; de Freitas, E.P.; Muller, I.; Winter, J.M.; Pereira, C.E. Design and Optimization of a Heterogeneous Platform for multiple UAV use in Precision Agriculture Applications. IFAC Proc. Vol. 2014, 47, 12272-12277. [CrossRef]

39. del Cerro, J.; Cruz Ulloa, C.; Barrientos, A.; de León Rivas, J. Unmanned Aerial Vehicles in Agriculture: A Survey. Agronomy 2021, 11, 203. [CrossRef]

40. Vu, Q.; Nguyen, V.; Solenaya, O.; Ronzhin, A. Group Control of Heterogeneous Robots and Unmanned Aerial Vehicles in Agriculture Tasks. In Proceedings of the International Conference on Interactive Collaborative Robotics (ICR 2017), Hatfield, UK, 12-16 September 2017; Ronzhin, A., Rigoll, G., Meshcheryakov, R., Eds.; Springer: Cham, Switzerland, 2017; Volume 10459, pp. 260-267, ISBN 978-3-319-66470-5.

41. Chao, H.; Baumann, M.; Jensen, A.; Chen, Y.; Cao, Y.; Ren, W.; McKee, M. Band-reconfigurable Multi-UAV-based Cooperative Remote Sensing for Real-time Water Management and Distributed Irrigation Control. IFAC Proc. Vol. 2008, 41, 11744-11749. [CrossRef]

42. Albani, D.; Manoni, T.; Arik, A.; Nardi, D.; Trianni, V. Field Coverage for Weed Mapping: Toward Experiments with a UAV Swarm. In Lecture Notes of the Institute for Computer Sciences, Social-Informatics and Telecommunications Engineering, LNICST; Springer: Berlin/Heidelberg, Germany, 2019; Volume 289, pp. 132-146, ISBN 9783030242015.

43. Albani, D.; IJsselmuiden, J.; Haken, R.; Trianni, V. Monitoring and mapping with robot swarms for agricultural applications. In Proceedings of the 2017 14th IEEE International Conference on Advanced Video and Signal Based Surveillance (AVSS), Lecce, Italy, 29 August-1 September 2017; pp. 1-6. 
44. Del Cerro, J.; Barrientos, A.; Sanz, D.; Valente, J. Aerial Fleet in RHEA Project: A High Vantage Point Contributions to ROBOT 2013; Armada, M.A., Sanfeliu, A., Ferre, M., Eds.; Advances in Intelligent Systems and Computing; Springer: Cham, Switzerland, 2014; Volume 252, ISBN 978-3-319-03412-6.

45. Valente, J.; Del Cerro, J.; Barrientos, A.; Sanz, D. Aerial coverage optimization in precision agriculture management: A musical harmony inspired approach. Comput. Electron. Agric. 2013, 99, 153-159. [CrossRef]

46. Ju, C.; Son, H. Il A distributed swarm control for an agricultural multiple unmanned aerial vehicle system. Proc. Inst. Mech. Eng. Part I J. Syst. Control Eng. 2019, 233, 1298-1308. [CrossRef]

47. Skobelev, P.; Budaev, D.; Gusev, N.; Voschuk, G. Designing Multi-agent Swarm of UAV for Precise Agriculture. In Highlights of Practical Applications of Agents, Multi-Agent Systems, and Complexity: The PAAMS Collection; Bajo, J., Corchado, J.M., Navarro Martínez, E.M., Osaba Icedo, E., Mathieu, P., Hoffa-Dąbrowska, P., del Val, E., Giroux, S., Castro, A.J.M., Sánchez-Pi, N., et al., Eds.; Communications in Computer and Information Science; Springer: Cham, Switzerland, 2018; Volume 887, pp. 47-59, ISBN 978-3-319-94778-5.

48. Barrientos, A.; Colorado, J.; del Cerro, J.; Martinez, A.; Rossi, C.; Sanz, D.; Valente, J. Aerial remote sensing in agriculture: A practical approach to area coverage and path planning for fleets of mini aerial robots. J. Field Robot. 2011, 28, 667-689. [CrossRef]

49. Drenjanac, D.; Tomic, S.D.K.; Klausner, L.; Kühn, E. Harnessing coherence of area decomposition and semantic shared spaces for task allocation in a robotic fleet. Inf. Process. Agric. 2014, 1, 23-33. [CrossRef]

50. Ju, C.; Son, H. Multiple UAV Systems for Agricultural Applications: Control, Implementation, and Evaluation. Electronics 2018, 7, 162. [CrossRef]

51. Ju, C.; Park, S.; Park, S.; Son, H. Il A Haptic Teleoperation of Agricultural Multi-UAV. In Proceedings of the Workshop on Agricultural Robotics: Learning from Industry 4.0 and Moving into the Future at the IEEE/RSJ International Conference on Intelligent Robots and Systems (IROS), Vancouver, BC, Canada, 28 September 2017; pp. 1-6.

52. Nolan, P.; Paley, D.A.; Kroeger, K. Multi-UAS path planning for non-uniform data collection in precision agriculture. In Proceedings of the 2017 IEEE Aerospace Conference, Big Sky, MT, USA, 4-11 March 2017; pp. 1-12.

53. Bochtis, D.D.; Sørensen, C.G.; Green, O.; Moshou, D.; Olesen, J. Effect of controlled traffic on field efficiency. Biosyst. Eng. 2010, 106, 14-25. [CrossRef]

54. Noguchi, N.; Will, J.; Reid, J.; Zhang, Q. Development of a master-slave robot system for farm operations. Comput. Electron. Agric. 2004, 44, 1-19. [CrossRef]

55. Zhang, X.; Geimer, M.; Noack, P.O.; Grandl, L. Development of an intelligent master-slave system between agricultural vehicles. In Proceedings of the 2010 IEEE Intelligent Vehicles Symposium, La Jolla, CA, USA, 21-24 June 2010; pp. 250-255.

56. Zhang, C.; Noguchi, N.; Yang, L. Leader-follower system using two robot tractors to improve work efficiency. Comput. Electron. Agric. 2016, 121, 269-281. [CrossRef]

57. Noguchi, N.; Barawid, O.C. Robot Farming System Using Multiple Robot Tractors in Japan Agriculture. IFAC Proc. Vol. 2011, 44, 633-637. [CrossRef]

58. Li, N.; Remeikas, C.; Xu, Y.; Jayasuriya, S.; Ehsani, R. Task Assignment and Trajectory Planning Algorithm for a Class of Cooperative Agricultural Robots. J. Dyn. Syst. Meas. Control 2015, 137, 1-9. [CrossRef]

59. Conesa-Muñoz, J.; Bengochea-Guevara, J.M.; Andujar, D.; Ribeiro, A. Route planning for agricultural tasks: A general approach for fleets of autonomous vehicles in site-specific herbicide applications. Comput. Electron. Agric. 2016, 127, 204-220. [CrossRef]

60. Blender, T.; Buchner, T.; Fernandez, B.; Pichlmaier, B.; Schlegel, C. Managing a Mobile Agricultural Robot Swarm for a seeding task. In Proceedings of the IECON 2016-42nd Annual Conference of the IEEE Industrial Electronics Society, Florence, Italy, 23-26 October 2016; pp. 6879-6886.

61. Anil, H.; Nikhil, K.S.; Chaitra, V.; Sharan, B.S.G. Revolutionizing Farming Using Swarm Robotics. In Proceedings of the 2015 6th International Conference on Intelligent Systems, Modelling and Simulation, Kuala Lumpur, Malaysia, 9-12 February 2015; pp. 141-147.

62. Janani, A.; Alboul, L.; Penders, J. Multi Robot Cooperative Area Coverage, Case Study: Spraying. In Lecture Notes in Computer Science; Springer: Berlin/Heidelberg, Germany, 2016; Volume 9716, pp. 165-176, ISBN 9783319403786.

63. Janani, A.; Alboul, L.; Penders, J. Multi-agent cooperative area coverage: Case study ploughing. In Proceedings of the 2016 International Conference on Autonomous Agents \& Multiagent Systems, AAMAS, Singapore, Singapore, 9-13 May 2016; pp. 1397-1398.

64. Tourrette, T.; Deremetz, M.; Naud, O.; Lenain, R.; Laneurit, J.; De Rudnicki, V. Close Coordination of Mobile Robots Using Radio Beacons: A New Concept Aimed at Smart Spraying in Agriculture. In Proceedings of the 2018 IEEE/RSJ International Conference on Intelligent Robots and Systems (IROS), Madrid, Spain, 1-5 October 2018; pp. 7727-7734.

65. Hameed, I.A. A Coverage Planner for Multi-Robot Systems in Agriculture. In Proceedings of the 2018 IEEE International Conference on Real-time Computing and Robotics (RCAR), Kandima, Maldives, 1-5 August 2018; pp. 698-704.

66. Arguenon, V.; Bergues-Lagarde, A.; Rosenberger, C.; Bro, P.; Smari, W. Multi-Agent Based Prototyping of Agriculture Robots. In Proceedings of the International Symposium on Collaborative Technologies and Systems (CTS'06), Las Vegas, NV, USA, 14-17 May 2006; Volume 2006, pp. 282-288.

67. Emmi, L.; Paredes-Madrid, L.; Ribeiro, A.; Pajares, G.; Gonzalez-de-Santos, P. Fleets of robots for precision agriculture: A simulation environment. Ind. Robot Int. J. 2013, 40, 41-58. [CrossRef] 
68. Iida, M.; Harada, S.; Sasaki, R.; Zhang, Y.; Asada, R.; Suguri, M.; Masuda, R. Multi-Combine Robot System for Rice Harvesting Operation. In Proceedings of the 2017 ASABE Annual International Meeting, Spokane, WA, USA, 16-19 July 2017; American Society of Agricultural and Biological Engineers: St. Joseph, MI, USA, 2017; pp. 1-5.

69. Teslya, N.; Smirnov, A.; Ionov, A.; Kudrov, A. Multi-robot Coalition Formation for Precision Agriculture Scenario Based on Gazebo Simulator. In Smart Innovation, Systems and Technologies; Springer: Berlin/Heidelberg, Germany, 2021; pp. 329-341, ISBN 9789811555794.

70. Davoodi, M.; Faryadi, S.; Velni, J.M. A Graph Theoretic-Based Approach for Deploying Heterogeneous Multi-agent Systems with Application in Precision Agriculture. J. Intell. Robot. Syst. 2021, 101, 10. [CrossRef]

71. Wu, C.; Chen, Z.; Wang, D.; Song, B.; Liang, Y.; Yang, L.; Bochtis, D.D. A Cloud-Based In-Field Fleet Coordination System for Multiple Operations. Energies 2020, 13, 775. [CrossRef]

72. Kim, J.; Son, H. Il A Voronoi Diagram-Based Workspace Partition for Weak Cooperation of Multi-Robot System in Orchard. IEEE Access 2020, 8, 20676-20686. [CrossRef]

73. Vu, Q.; Raković, M.; Delic, V.; Ronzhin, A. Trends in Development of UAV-UGV Cooperation Approaches in Precision Agriculture. In Lecture Notes in Computer Science (Including Subseries Lecture Notes in Artificial Intelligence and Lecture Notes in Bioinformatics); Springer: Berlin/Heidelberg, Germany, 2018; Volume 11097 LNAI, pp. 213-221, ISBN 9783319995816.

74. Menendez-Aponte, P.; Garcia, C.; Freese, D.; Defterli, S.; Xu, Y. Software and hardware architectures in cooperative aerial and ground robots for agricultural disease detection. In Proceedings of the 2016 International Conference on Collaboration Technologies and Systems (CTS), Orlando, FL, USA, 31 October-4 November 2016; pp. 354-358. [CrossRef]

75. Tokekar, P.; Hook, J.V.; Mulla, D.; Isler, V. Sensor Planning for a Symbiotic UAV and UGV System for Precision Agriculture. IEEE Trans. Robot. 2016, 32, 1498-1511. [CrossRef]

76. Ni, J.; Wang, X.; Tang, M.; Cao, W.; Shi, P.; Yang, S.X. An Improved Real-Time Path Planning Method Based on Dragonfly Algorithm for Heterogeneous Multi-Robot System. IEEE Access 2020, 8, 140558-140568. [CrossRef]

77. Li, J.; Deng, G.; Luo, C.; Lin, Q.; Yan, Q.; Ming, Z. A Hybrid Path Planning Method in Unmanned Air/Ground Vehicle (UAV/UGV) Cooperative Systems. IEEE Trans. Veh. Technol. 2016, 65, 9585-9596. [CrossRef]

78. Peterson, J.; Li, W.; Cesar-Tondreau, B.; Bird, J.; Kochersberger, K.; Czaja, W.; McLean, M. Experiments in unmanned aerial vehicle/unmanned ground vehicle radiation search. J. Field Robot. 2019, 36, 818-845. [CrossRef]

79. Wang, Z.; McDonald, S.T. Convex relaxation for optimal rendezvous of unmanned aerial and ground vehicles. Aerosp. Sci. Technol. 2020, 99, 105756. [CrossRef]

80. Conesa-Muñoz, J.; Valente, J.; del Cerro, J.; Barrientos, A.; Ribeiro, A. A Multi-Robot Sense-Act Approach to Lead to a Proper Acting in Environmental Incidents. Sensors 2016, 16, 1269. [CrossRef]

81. Gonzalez-de-Santos, P.; Ribeiro, A.; Fernandez-Quintanilla, C.; Lopez-Granados, F.; Brandstoetter, M.; Tomic, S.; Pedrazzi, S.; Peruzzi, A.; Pajares, G.; Kaplanis, G.; et al. Fleets of robots for environmentally-safe pest control in agriculture. Precis. Agric. 2017, 18, 574-614. [CrossRef]

82. Potena, C.; Khanna, R.; Nieto, J.; Nardi, D.; Pretto, A. Collaborative UAV-UGV Environment Reconstruction in Precision Agriculture. In Proceedings of the IEEE/RSJ IROS Workshop" Vision-Based Drones: What's Next, Madrid, Spain, 1-5 October 2018; pp. 1-6.

83. Potena, C.; Khanna, R.; Nieto, J.; Siegwart, R.; Nardi, D.; Pretto, A. AgriColMap: Aerial-Ground Collaborative 3D Mapping for Precision Farming. IEEE Robot. Autom. Lett. 2019, 4, 1085-1092. [CrossRef]

84. Bhandari, S.; Raheja, A.; Green, R.L.; Do, D. Towards collaboration between unmanned aerial and ground vehicles for precision agriculture. In Proceedings of the Autonomous Air and Ground Sensing Systems for Agricultural Optimization and Phenotyping II, Anaheim, CA, USA, 10-11 April 2017; Thomasson, J.A., McKee, M., Moorhead, R.J., Eds.; International Society for Optics and Photonics: Bellingham, WA, USA, 2017; Volume 10218, p. 1021806.

85. Grassi, R.; Rea, P.; Ottaviano, E.; Maggiore, P. Application of an Inspection Robot Composed by Collaborative Terrestrial and Aerial Modules for an Operation in Agriculture. In Mechanisms and Machine Science; Springer: Berlin/Heidelberg, Germany, 2018; Volume 49, pp. 539-546. ISBN 9783319612751.

86. Vasudevan, A.; Kumar, D.A.; Bhuvaneswari, N.S. Precision farming using unmanned aerial and ground vehicles. In Proceedings of the 2016 IEEE Technological Innovations in ICT for Agriculture and Rural Development (TIAR), Chennai, India, 15-16 July 2016; pp. 146-150.

87. Ju, C.; Son, H. Il Hybrid Systems based Modeling and Control of Heterogeneous Agricultural Robots for Field Operations. In Proceedings of the 2019 ASABE Annual International Meeting, Boston, MA, USA, 7-10 July 2019; American Society of Agricultural and Biological Engineers: St. Joseph, MI, USA, 2019; pp. 3-15.

88. Williams, H.A.M.; Jones, M.H.; Nejati, M.; Seabright, M.J.; Bell, J.; Penhall, N.D.; Barnett, J.J.; Duke, M.D.; Scarfe, A.J.; Ahn, H.S.; et al. Robotic kiwifruit harvesting using machine vision, convolutional neural networks, and robotic arms. Biosyst. Eng. 2019, 181, 140-156. [CrossRef]

89. Zion, B.; Mann, M.; Levin, D.; Shilo, A.; Rubinstein, D.; Shmulevich, I. Harvest-order planning for a multiarm robotic harvester. Comput. Electron. Agric. 2014, 103, 75-81. [CrossRef]

90. Xiong, Y.; Ge, Y.; Grimstad, L.; From, P.J. An autonomous strawberry-harvesting robot: Design, development, integration, and field evaluation. J. Field Robot. 2020, 37, 202-224. [CrossRef] 
91. Sarabu, H.; Ahlin, K.; Hu, A.-P. Graph-Based Cooperative Robot Path Planning in Agricultural Environments. In Proceedings of the 2019 IEEE/ASME International Conference on Advanced Intelligent Mechatronics (AIM), Hong Kong, China, 8-12 July 2019; pp. 519-525.

92. Ahlin, K.J.; Hu, A.-P.; Sadegh, N. Apple Picking Using Dual Robot Arms Operating Within an Unknown Tree. In Proceedings of the 2017 ASABE Annual International Meeting, Spokane, WA, USA, 16-19 July 2017; American Society of Agricultural and Biological Engineers: St. Joseph, MI, USA, 2017; pp. 1-11.

93. Sepulveda, D.; Fernandez, R.; Navas, E.; Armada, M.; Gonzalez-De-Santos, P. Robotic Aubergine Harvesting Using Dual-Arm Manipulation. IEEE Access 2020, 8, 121889-121904. [CrossRef]

94. Davidson, J.R.; Hohimer, C.J.; Mo, C.; Karkee, M. Dual robot coordination for apple harvesting. In Proceedings of the 2017 ASABE Annual International Meeting, Spokane, WA, USA, 16-19 July 2017; pp. 1-9. [CrossRef]

95. Ling, X.; Zhao, Y.; Gong, L.; Liu, C.; Wang, T. Dual-arm cooperation and implementing for robotic harvesting tomato using binocular vision. Rob. Auton. Syst. 2019, 114, 134-143. [CrossRef]

96. Pramod, A.S.; Jithinmon, T.V. Development of mobile dual PR arm agricultural robot. J. Phys. Conf. Ser. 2019, $1240,012034$. [CrossRef]

97. BACCHUS-Mobile Robotic Platforms for Active Inspection \& Harvesting in Agricultural Areas. European Union's Horizon 2020 research and innovation programme under grant agreement No 871704. Available online: https://bacchus-project.eu/ (accessed on 10 May 2021).

98. Kaburlasos, V.G. The Lattice Computing (LC) Paradigm. In Proceedings of the Fifthteenth International Conference on Concept Lattices and Their Applications (CLA 2020), Tallinn, Estonia, 29 June-1 July 2020; Volume 2668, pp. 1-7.

99. Bazinas, C.; Vrochidou, E.; Lytridis, C.; Kaburlasos, V.G. Time-Series of Distributions Forecasting in Agricultural Applications: An Intervals' Numbers Approach. Eng. Proc. 2021, 5, 12. [CrossRef] 